\title{
Mechanisms of bottom boundary fluxes in a numerical model of the Shetland shelf
}

\author{
Arjav Trivedi $^{1}$ (D) $\cdot$ Ralf Toumi $^{1}$
}

Received: 6 November 2015 / Accepted: 17 October 2016 / Published online: 26 November 2016

(C) The Author(s) 2016. This article is published with open access at Springerlink.com

\begin{abstract}
Across-slope bottom boundary layer (BBL) fluxes on the shelf-edge connect this region to deeper waters. Two proposed ways in which across-slope BBL fluxes can occur, in regions that have a slope current aligned to the bathymetry, are the frictional veering of bottom currents termed the 'Ekman drain' and through local windforced downwelling (wind-driven surface Ekman flow with an associated bottom flow). We investigate the variability, magnitude and spatial scale of BBL fluxes on the Shetland shelf, which has a prominent slope current, using a highresolution $(\sim 2 \mathrm{~km})$ configuration of the MITgcm model. Fluxes are analysed in the BBL at the shelf break near the $200 \mathrm{~m}$ isobath and are found to have a seasonal variability with high/low volume transport in winter/summer respectively. By using a multivariate regression approach, we find that the locally wind-driven Ekman transport plays no explicit role in explaining daily bottom fluxes. We can better explain the variability of the across-slope BBL flux as a linear function of the speed and across-slope component of the interior flow, corresponding to an Ekman plus mean-flow flux. We estimate that the mean-flow is a greater contributor than the Ekman flux to the BBL flux. The spatial heterogeneity of the BBL fluxes can be attributed to the mean-flow, which has a much shorter decorrelation length compared to the Ekman flux. We conclude that both the
\end{abstract}

Responsible Editor: Dieter Wolf-Gladrow

Arjav Trivedi

arjav.trivedi09@imperial.ac.uk

1 Blackett Laboratory, Imperial College London, London SW7 2AZ, UK speed and direction of the interior current determines the daily BBL flux. The wind does not explicitly contribute through local downwelling, but may influence the interior current and therefore implicitly the BBL fluxes on longer timescales.

Keywords Ekman drain - Multivariate regression . Faroe-Shetland Channel · Regional ocean model

\section{Introduction}

Holt et al. (2009) modelled the entire north-western European continental shelf to study bottom boundary layer (BBL) fluxes on the shelf-edge. They identified a regional downwelling circulation with two parts: wind-driven, onshelf transport leading to downwelling and local, off-shelf transport in a near-bed Ekman layer, termed the 'Ekman drain' (Souza et al. 2001). Observations by Simpson and McCandliss (2013) on the Hebridean shelf edge have contributed towards evidence of an 'Ekman drain'. Meanders of the regional slope current (Sherwin et al. 1999, 2006) and eddies are considered elements of across-slope transport (Huthnance et al. 2009) over the entire shelf-sea depth, but not specifically in the BBL.

Fluxes near the shelf break are important as they connect shallower shelf seas to deeper waters. Shelf seas play a significant role in the uptake of atmospheric $\mathrm{CO}_{2}$ (Thomas et al. 2004; Ryther 1969). Tsunogai et al. (1999) proposed the continental shelf pump mechanism in an attempt to explain why this is the case. As part of it, the annual absorption of atmospheric $\mathrm{CO}_{2}$ into shallow shelf seas requires it to be transported off-shelf to deeper waters. The development of a seasonal pycnocline inhibits this off-shelf transport in the ocean layers above the pycnocline, but not below. So in a 
near-bed bottom boundary layer, export of carbon off-shelf can occur year-round. The hydrodynamic processes responsible for BBL volume fluxes contribute to the sustained off-shelf export of carbon near the seabed.

Observations of carbon uptake on sections of the northwestern European shelf (such as the North Sea) find it to be a carbon sink (Frankignoulle and Borges 2001; Bozec et al. 2005). There is also evidence that the carbon on this shelf region is exported off-shelf, consistent with the continental shelf pump hypothesis (Thomas et al. 2004; Bozec et al. 2005). The Shetland shelf, part of the larger European continental shelf, is therefore an interesting and relevant region to study hydrodynamic shelf-edge BBL fluxes (which impact on the carbon fluxes).

The Shetland shelf is one side of the Faroe-Shetland Channel (FSC): a deep bathymetric channel extending north-eastwards between Scotland and the Faroe Islands
(Fig. 1). A prominent feature is the Continental Slope Current. It has a high-speed core (Hansen and Østerhus 2000; Berx et al. 2013) with current speeds increasing from 10 to $20 \mathrm{~cm} \mathrm{~s}^{-1}$ at the shelf-break (around $200 \mathrm{~m}$; Dooley et al. 1976; Turrell et al. 1992) to $40 \mathrm{~cm} \mathrm{~s}^{-1}$ over the $1000 \mathrm{~m}$ contour (Dooley et al. 1976). It is vertically coherent being predominantly barotropic to depths of $500 \mathrm{~m}$ and is composed of North Atlantic Water (Sherwin et al. 2008). It is continuous along the shelf-edge, existing from the Hebridean shelf-edge (Souza et al. 2001) with its origins as far south as the Brittany peninsula (Pingree and Le Cann 1989). Observations (e.g. Sherwin et al. 1999, 2006) and model studies (Oey 1998) of the slope current have identified mesoscale meanders and eddies, identifying them as important in the across-shelf transport and mixing of slope current water with Modified North Atlantic Water located on the Faroe Plateau (Sherwin et al. 1999). Meanders on

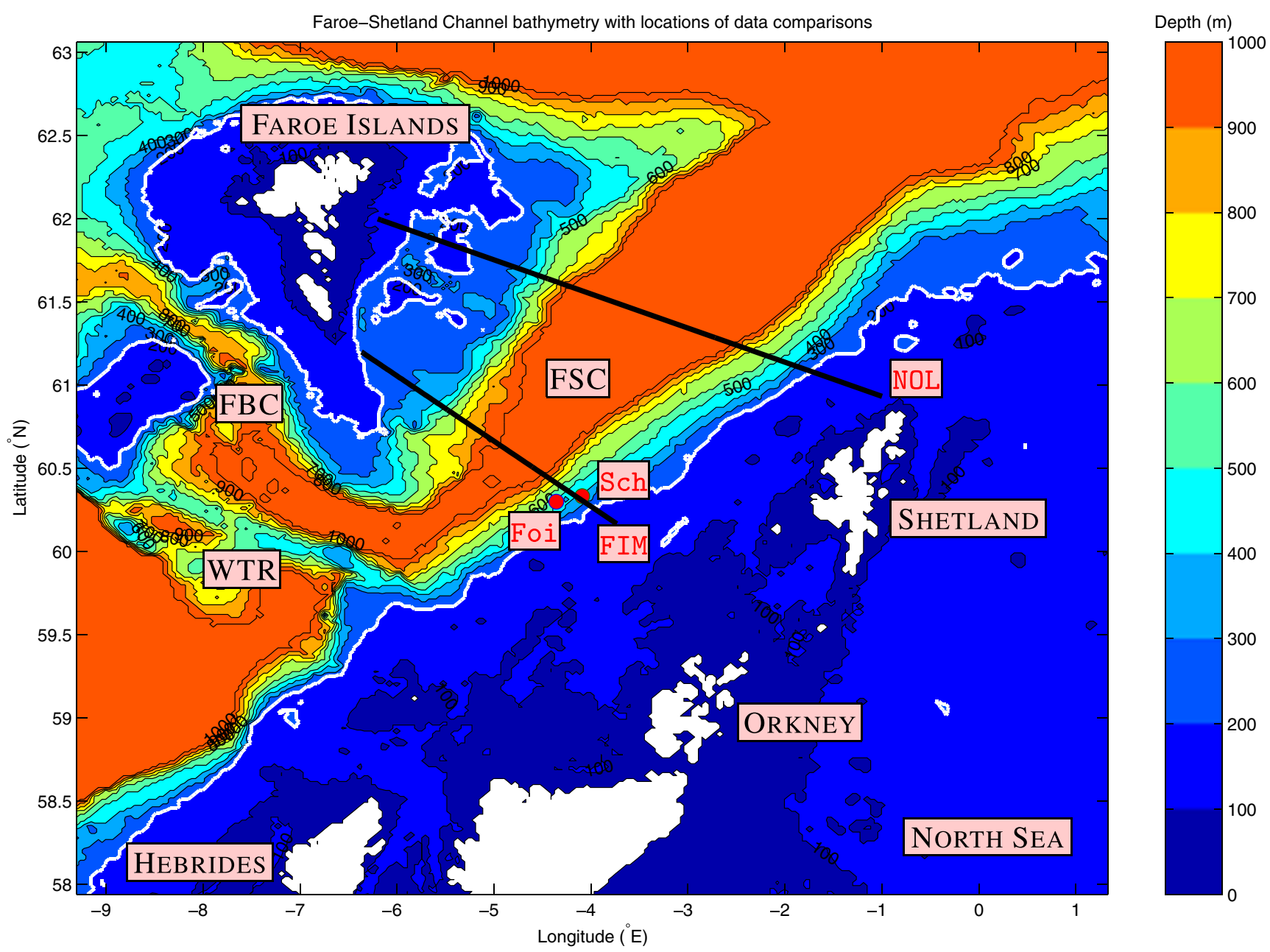

Fig. 1 Model domain and bathymetry (Sandwell and Smith 1997) of the Faroe-Shetland Channel (FSC) to $1000 \mathrm{~m}$ depth. Red dots indicate locations of Foinhaven/Schiehallion (Foi/Sch) current observations. Black lines represent the Fair Isle-Munken/Nolso-Flugga (FIM/NOL) observational cross-sections. The white line highlights the $200 \mathrm{~m}$ isobath. The Faroe-Bank Channel (FBC), Wyville-Thompson Ridge (WTR), Faroe Islands, Orkney Islands, Shetland Islands, Hebrides and North Sea are also labelled here for geographical context 
short timescales $(\sim$ days) are theorised to be caused by baroclinic instability (Sherwin et al. 2006). On interannual timescales increased cross-shelf transport is associated with the negative mode of the North Atlantic Oscillation (Chafik 2012).

There are several gaps in our knowledge. Firstly, we do not know the seasonal variability of BBL transport on the shelf-edge. Secondly, the hydrodynamic processes responsible for BBL fluxes have been identified, such as the Ekman drain and downwelling-however in the simple Ekman drain model (Souza et al. 2001), poor correlations and a large variability have been noted between across-slope BBL and calculated Ekman transports (Holt et al. 2009; Simpson and McCandliss 2013) despite an apparently consistent slope current flowing parallel to the slope. What causes the short-term variability in the Ekman-drain model? Furthermore, Holt et al. (2009) propose that the contribution of the wind to BBL fluxes should be valid across many shelf seas. However in the south-eastern Australian shelf Schaeffer et al. (2014) have rejected the wind as a contributor. Can a wind-driven Ekman term, potentially driving a classical 2D coastal downwelling, help to understand BBL fluxes on the Shetland shelf-edge which is part of the north-western European continental shelf? Finally, we do not know the spatial scales of the hydrodynamic processes contributing to BBL fluxes - can they be understood locally, or only in the context of shelf-integrated transport?

Using a high-resolution regional ocean model of the Faroe-Shetland Channel, our study investigates the variability, magnitude and spatial scale of across-slope BBL transport on the Shetland shelf with three aims. Firstly, what is the seasonal variability of BBL transport on the Shetland shelf? Secondly, building on the previous work of Holt et al. (2009) can we confirm the Ekman-drain model in a higher resolution model and, for the first time, identify and quantify the cause of the observed variability (Simpson and McCandliss 2013) of across-slope bottom transport? Finally can we, for the first time, demonstrate the contribution of local wind-forced downwelling on the across-slope BBL flux for the Shetland shelf?

\section{Method}

\subsection{Model setup}

Our study used the Massachusetts Institute of Technology General Circulation Model (MITgcm) (Marshall et al. 1997) configured on a spherical grid from $58^{\circ} \mathrm{N}$ to $63^{\circ} \mathrm{N}$ and $-9^{\circ} \mathrm{E}$ to $1^{\circ} \mathrm{E}$, with horizontal grid spacing approximately $2 \mathrm{~km}$ in zonal and meridional directions. We used 35 vertical layers distributed as follows: $10 \times 10 \mathrm{~m}(0$ to $100 \mathrm{~m}), 5 \times 20 \mathrm{~m}$ (100 to $200 \mathrm{~m}), 10 \times 40 \mathrm{~m}(200$ to $600 \mathrm{~m}), 5 \times 80 \mathrm{~m}$ (600 to
$1000 \mathrm{~m}), 4 \times 250 \mathrm{~m}$ (1000 to $2000 \mathrm{~m}), 1 \times 450 \mathrm{~m}(2000 \mathrm{~m}$ to the seabed). These layers were outcropped by bathymetry (Fig. 1) from Sandwell and Smith (1997).

The model was initialised and forced at the lateral boundaries by daily oceanic fields (temperature, salinity, north/eastward currents) provided by the HYbrid Coordinate Ocean Model (HYCOM) reanalysis (Chassignet et al. 2007). Initial and hourly atmospheric forcing was provided by Climate Forecast System Reanalysis (CFSR) (Saha et al. 2010). Our simulation ran from 1st January 2002 to 31st December 2006; this period was chosen as it had good overlap with our current observations. To mitigate for model spin-up, we have discarded results from 2002, so the results shown in this study are for the 4-year period from 2003 to 2006.

We did not explicitly force with tides, so to mitigate major tidal effects we averaged our currents daily. Our horizontal eddy viscosity was $5 \times 10^{-4} \mathrm{~m}^{2} \mathrm{~s}^{-1}$. Larger values resulted in poorer validation. Vertical eddy viscosities were parameterised using the KPP vertical mixing scheme (Large et al. 1994) with a background viscosity of $1 \times 10^{-4} \mathrm{~m}^{2} \mathrm{~s}^{-1}$. Our simulations ran in hydrostatic mode because non-hydrostatic runs had no appreciable difference in validation. For the surface boundary condition we used an implicit linear free-surface. For the bottom boundary, we used a free-slip condition with an explicit quadratic drag coefficient of $2.5 \times 10^{-3}$.

\subsection{Orientation}

We focus on fluxes crossing the $200 \mathrm{~m}$ isobath and split the isobath into many 'stations' interpolated from the model grid points that effectively act as proxies for observation sites. We define our BBL as the 180 to $200 \mathrm{~m}$ layer. At a given station the across-slope BBL flux, $Q_{B B L}=V_{B B L} \times$ $h_{B B L}$, where $V_{B B L}$ is the across-slope BBL current (Fig. 2) and $h_{B B L}$ is the BBL height $(20 \mathrm{~m})$. To calculate $V_{B B L}$ we need to know the slope angle, $\theta_{s}$, so we can orientate our eastward and northward currents to the local along/across-slope directions. We used two methods to determine $\theta_{s}$ at a given station. For the Local Gradient $(L G)$ slope angle $\left(\theta_{S}^{L G}\right)$, we interpolate latitude and longitude midway between stations (black dots in Fig. 2) to calculate the angle, relative to east, between these points: so $\theta_{s}^{L G}=\theta^{L G}$ (Fig. 2). To calculate the Taylor-Proudman Theorem (TPT) slope angle $\left(\theta_{S}^{T P T}\right)$, we use the result that geostrophic flow on an $f$-plane follows isobaths. We assume the interior current $\mathbf{V}_{\text {int }}$ is geostrophic. The angle it makes relative to east is $\theta^{T P T}$, so we set the slope angle $\theta_{S}^{T P T}$ to be the timemean of $\theta^{T P T}$; or $\theta_{s}^{T P T}=\left\langle\theta^{T P T}\right\rangle$ where $\langle\ldots\rangle$ denotes time-averaging. This method is also an approximation to the LG method that we consider exact (given the model resolution), and is used by Simpson and McCandliss (2013) in 


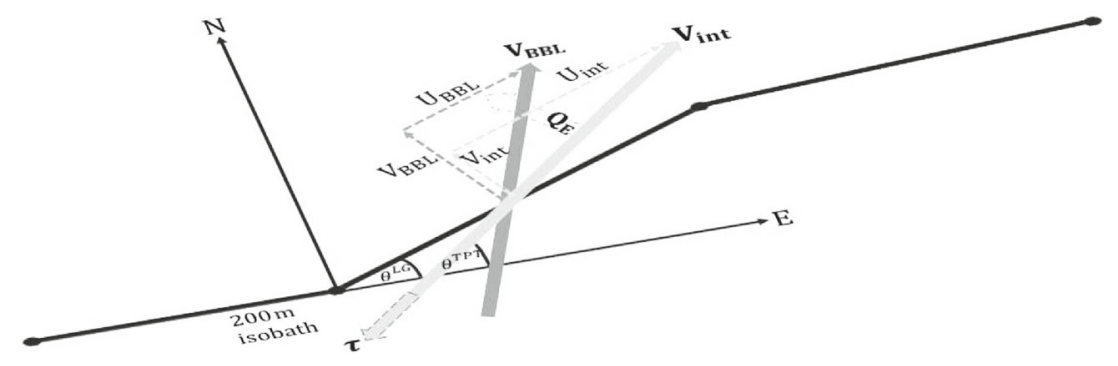

Fig. 2 Diagram of currents centred on a section of the $200 \mathrm{~m}$ isobath. Our study is 2-dimensional locally (no arrows have a vertical component) but we project into 3-dimensions for context: the $200 \mathrm{~m}$ isobath divides on- and off-shelf waters. The interior slope current, $\mathbf{V}_{\text {int }}$ (thick

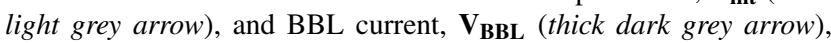
are decomposed into their along- and across-slope components (thin dashed arrows). $V_{B B L}$ corresponds to the across-slope BBL flux. $U_{\text {int }}$

their study of BBL fluxes. We aim to understand how the flux estimates depend on the orientation method.

\subsection{Fluxes}

We model $Q_{B B L}$ (the BBL flux over the 180 to $200 \mathrm{~m}$ layer) as a function of the current above the $20 \mathrm{~m} \mathrm{BBL}$ layer. This current is termed the interior current or $\mathbf{V}_{\mathbf{i n t}}$, and is calculated as the depth-averaged current in an $80 \mathrm{~m}$ layer (100 to $180 \mathrm{~m}$ ) above the BBL. We chose an $80 \mathrm{~m}$ layer because we want to sufficiently capture the mean flow in the ocean interior, be far away from the surface Ekman layer and to minimise against any bottom boundary effects that may pervade into the next vertical cell.

In the absence of friction, and away from lateral boundaries, the interior current $\mathbf{V}_{\text {int }}$ should extend to the seabed. Then the across-slope BBL flux, $Q_{B B L}$, can be estimated from the mean flow, that is, the across-slope component of the interior current $V_{\text {int }}$ (Section 3.4.3).

In the presence of friction, an Ekman spiral develops where the current is deflected due to the effect of the bottom stress. The vertical integral of the Ekman spiral gives a transport that is perpendicular to the mean-flow. For brevity, we will call this vertically integrated layer the veering layer. For this layer a bottom stress, $\tau$, opposes the direction of $\mathbf{V}_{\text {int }}$, and so veers the BBL current to the left of the interior current in the Northern Hemisphere. This is quantified by a veering angle, $\theta_{\text {veer }}$. The veering also corresponds to an Ekman flux that can be modelled as,

$Q_{E}=\frac{\tau}{\rho f}$

where $Q_{E}$ denotes the Ekman flux (dimensions $\mathrm{L}^{2} \mathrm{~T}^{-1}$ ) perpendicular to the bottom stress $\tau$, with $\rho$ the density and $f$ the Coriolis parameter. As we would like a simpler representation of the across-slope BBL flux as a function of interior and $V_{\text {int }}$ are the along- and across-slope components of the interior flow. The slope angle is given from the bathymetry $\left(\theta^{L G}\right)$ or using the Taylor-Proudman Theorem (calculated from the time-mean of $\theta^{T P T}$ ). A bottom stress $\tau$ (thick light grey dashed arrow) opposes the interior current and induces a perpendicular Ekman flux $Q_{E}$ (thick pale dashed arrow)

current components, we model $\tau$ as a quadratic function of the interior velocity,

$\tau=\rho \gamma_{2} \mathbf{V}_{\text {int }}^{2}$

where $\gamma_{2}$ is a dimensionless quadratic drag coefficient. Then the across-slope Ekman flux, $Q_{E}^{\perp}$, is caused by $\tau^{\|}$, the component of the bottom stress parallel to the slope. Taking $\theta$ to be the angle between $\mathbf{V}_{\text {int }}$ and the slope, $\tau^{\|}$is then

$$
\begin{aligned}
\tau^{\|} & =\tau \cos \theta=\rho \gamma_{2} \mathbf{V}_{\text {int }}^{\mathbf{2}} \cos \theta=\rho \gamma_{2} U_{\text {int }}\left|\mathbf{V}_{\text {int }}\right| \\
& \Rightarrow Q_{E}^{\perp}=\frac{\gamma_{2} U_{\text {int }}\left|\mathbf{V}_{\text {int }}\right|}{f}
\end{aligned}
$$

where $U_{\text {int }}$ is the along-slope component of the interior current. Alternatively, we can model $\tau$ as a linear function of the interior velocity, so

$\tau=\rho \gamma_{1} \mathbf{V}_{\text {int }} \Rightarrow Q_{E}^{\perp}=\frac{\gamma_{1} U_{i n t}}{f}$

where $\gamma_{1}$ is a linear drag coefficient with dimensions $\mathrm{LT}^{-1}$. In the presence of tides, the bottom stress can be parameterised linearly (Bowden 1953; Hunter 1975) though we have neglected them here. We investigate both linear and quadratic $\tau$ parameterisations for our model of BBL fluxes (Section 3.4.1) to see if there are any differences in approach.

An additional flux considered by Holt et al. (2009) and Schaeffer et al. (2014) is a wind-driven two-dimensional downwelling circulation. Here, a local wind-driven surface Ekman transport (that is perpendicular to the $200 \mathrm{~m}$ isobath), $Q_{W}^{\perp}$, may lead to an additional BBL flux below. We model this additional flux similarly to Eq. 3, with the interior current replaced by the $10 \mathrm{~m}$ surface wind components parallel to the $200 \mathrm{~m}$ isobath. We use the same CFSR surface wind fields as used previously for model atmospheric forcing (Section 2.1) and consider separately the contribution of wind to the BBL flux (Section 3.4.5). 


\subsection{Regression model}

To test the simple Ekman drain model, we perform a univariate linear regression between BBL and Ekman fluxes (Section 3.4.1). However, we wish to quantify for the first time the effect the across-slope interior flow has on the BBL flux (Section 3.4.4). We propose a multivariate linear regression model

$Q_{B B L}=\Gamma Q_{E}^{\perp}+\alpha V_{i n t}+C+\epsilon$

where we decompose $Q_{B B L}$ into an Ekman variable $\left(Q_{E}^{\perp}\right)$ and a variable which characterises the mean flow, $V_{i n t}$, which corresponds to the across-slope component of the interior flow. These variables have regression coefficients $\Gamma$ and $\alpha$. The unaccounted physics in the regression model can overall be characterised by an intercept, $C$. The first three terms provide a best fit of the data; the additional variability of any individual datum around this best fit is given by the $\epsilon$ term, or residual. In Section 3.4.5 ,a wind-driven Ekman term, $Q_{W}^{\perp}=\frac{\rho_{\text {air }}}{\rho} \frac{\gamma_{\text {wind }} U_{\text {wind }}\left|\mathbf{V}_{\text {wind }}\right|}{f}$, is added to the multivariate regression of Eq. 5 .

Performing this regression for each station yields local coefficients for the Ekman/interior flux variables (Section 3.4.4). Alternatively, we can integrate $Q_{B B L}, Q_{E}^{\perp}$ and $V_{\text {int }}$ along the entire shelf to calculate integrated transport terms, then perform a regression that yields global coefficients for a single shelf-integrated transport model (Section 3.5). The $R^{2}$-value of the regression model indicates whether the independent variables can explain the variability in the dependent variable. As increasing numbers of parameters may artificially inflate the ordinary- $R^{2}$ in the regression model, we quote the adjusted- $R^{2}$ which accounts for different numbers of parameters.

In this study, we quote sample estimates as the mean \pm 1 standard deviation, or $\bar{x} \pm s$. However, some distributions (e.g. $R^{2}$ for different locations) are not normal—so we quote the sample mean with interquartile range (IQR), or $\bar{x}\left[\mathrm{IQR}_{25} \%, \mathrm{IQR}_{75} \%\right]$. We perform hypothesis tests at the $1 \%$ significance level and where appropriate provide $99 \%$ confidence intervals (CI).

\subsection{Decorrelation length scale}

The decorrelation length scale is the distance over which two time-series are sufficiently far apart so that they are independent. This distance can help identify processes and instruct how far apart measurements have to be to optimise data collection to prevent spatial aliasing (Brink and Robinson 2005). We use this length scale to diagnose the horizontal scales of variability for Ekman, BBL, $V_{i n t}$ and residual transports. We performed two methods of decorrelation for variables in our regression model (5). Our first method finds the correlation coefficient, $r$, of the flux (BBL,
Ekman, $V_{\text {int }}$, residual) between all pairs of stations and bins this by the distance between the stations. For each bin we calculate the mean correlation (plus/minus one standard deviation). The mean (plus/minus one standard deviation) correlation per bin is a function of distance, and we infer the decorrelation length scale from the $e$-folding distance. The second method calculates the normalised root-mean square difference (RMSD) of the Ekman time-series between all pairs of stations. Normalisation is given by dividing the RMSD by the mean of the first time-series. For a given distance, the minimal-RMSD quantifies the maximal similarity of any two time-series along the shelf. The minimal-RMSD starts small and grows with distance. Where this growth stops (or continues to rise to a far-field value slowly) is the decorrelation length scale (Böhme and Send 2005).

\section{Results}

\subsection{Model validation}

\subsubsection{Mean currents}

A slope current directed north-eastwards can be seen at $190 \mathrm{~m}$ (Fig. 3). Sherwin et al. (2006) observe the fastest currents on average are near $61.25^{\circ} \mathrm{N},-2^{\circ} \mathrm{E}$ from archive drifter data. In our model, the fastest section of the slope current (average speed $>0.40 \mathrm{~m} \mathrm{~s}^{-1}$ ) is further downstream. The slope current has two fast sections (average speed $>0.30 \mathrm{~m} \mathrm{~s}^{-1}$ ) split around $60.5^{\circ} \mathrm{N},-3.5^{\circ} \mathrm{E}$. The circulation is also concentrated near $60^{\circ} \mathrm{N},-6^{\circ} \mathrm{E}$; this flow comes from the Wyville-Thompson Ridge (WTR) region and from the Faroe-Bank Channel (FBC). There is also a bifurcation (or meander) in the mean circulation at $60.5^{\circ} \mathrm{N}$, $-5^{\circ} \mathrm{E}$. This meander has been observed by Sherwin et al. (2006) in the mean current flow of drifters and from sea surface temperature (SST) snapshots, and by Sherwin et al. (2008) over a week-long composite of SST fronts. East of the Faroe plateau there is a clockwise circulation of flow south-westwards, a well-known feature in the region (e.g. Hansen and Østerhus 2000). A persistent eddy appears on the northern boundary at $62.75^{\circ} \mathrm{N},-1.5^{\circ} \mathrm{E}$. This could be caused by the HYCOM velocity boundary conditions on the northern boundary interacting with the strong slope current.

\subsubsection{Sea surface temperature}

Mean model SST is compared with observations (Fig. 4) from the Group for High Resolution Sea-Surface Temperature (GHRSST; Donlon et al. 2009). The model has a warm bias with a mean anomaly of $(0.09 \pm 0.67){ }^{\circ} \mathrm{C}$. In a previous model study using the Regional Ocean Modelling 


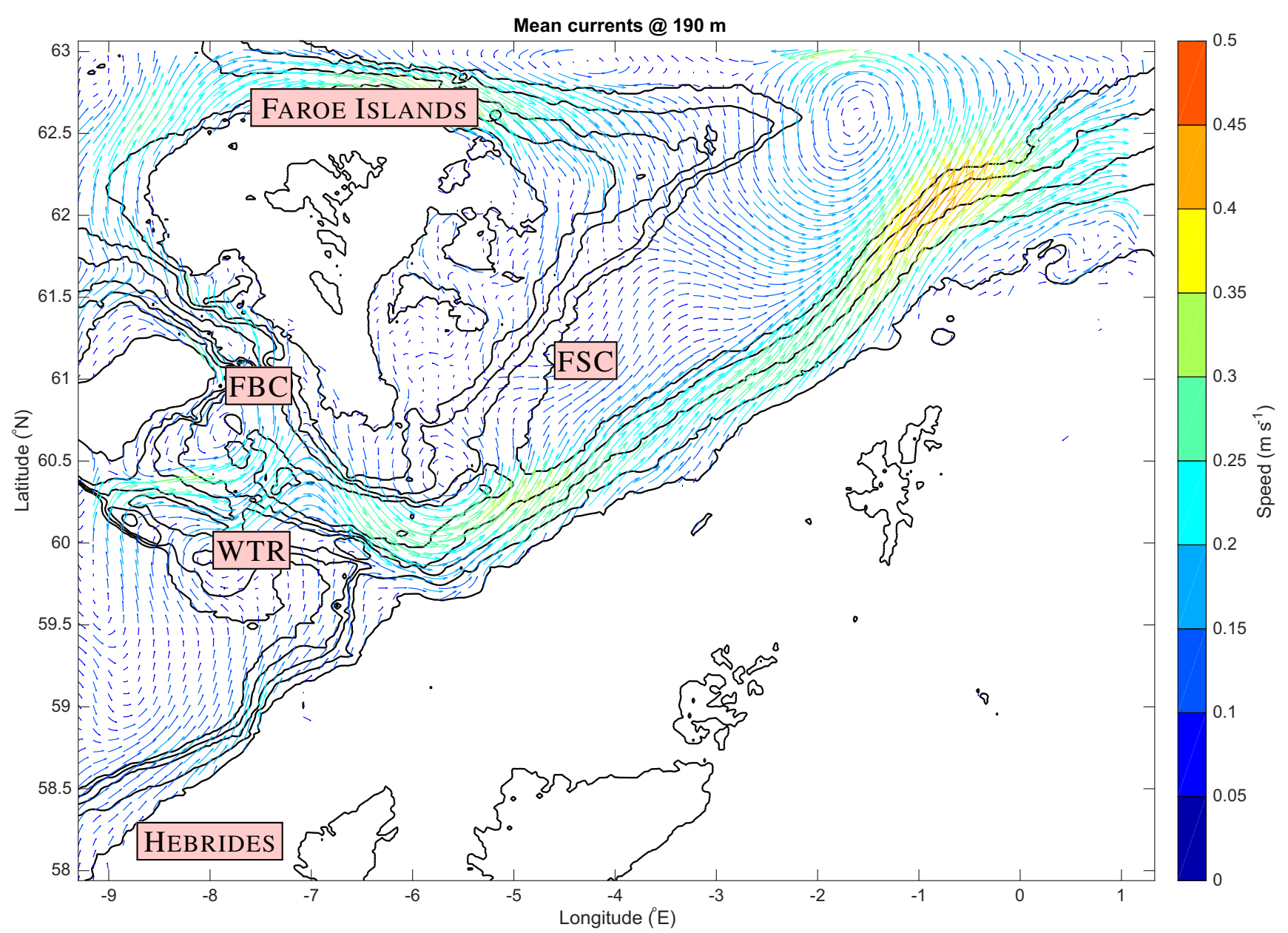

Fig. 3 Mean (2003-2006) U/V model currents at $190 \mathrm{~m}$. This is the depth used to calculate the BBL fluxes. Bathymetry contours are given every $200 \mathrm{~m}$ from sea-level to $1000 \mathrm{~m}$

System (ROMS), Broadbridge and Toumi (2015) show a cold bias for 2005 of $-0.77^{\circ} \mathrm{C}(-1.93,-0.15)^{\circ} \mathrm{C}$ where there they give the range. Some basic spatial structures are captured by the model: (i) a strong meridional temperature gradient between the northern Hebrides and southern
Faroes; (ii) the north-eastward extension of the 9 to $10{ }^{\circ} \mathrm{C}$ isotherms; (iii) the warmest water $\left(T>11^{\circ} \mathrm{C}\right)$ located west of the Hebrides and coldest water $\left(T<9^{\circ} \mathrm{C}\right)$ north of the Faroes. The model is warmer compared to observations towards the northern boundary, with the largest warm (a)

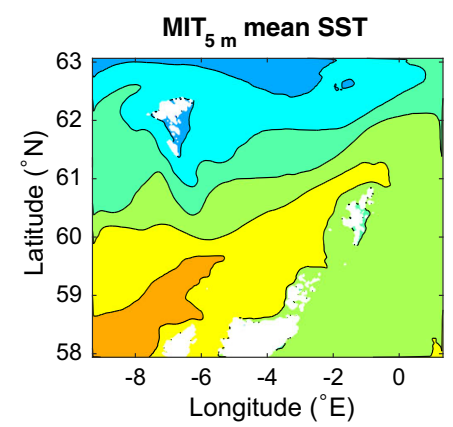

(b)

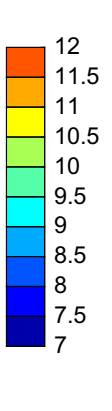

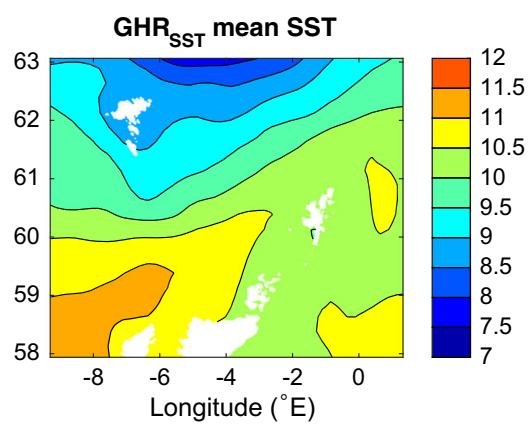

(c)

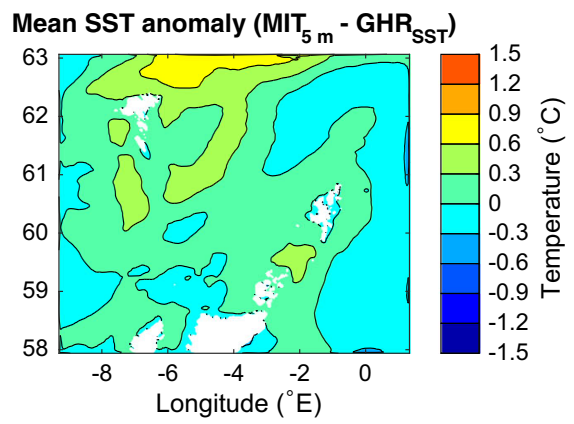

Fig. 4 Mean (2003-2006) SSTs for a our model, b GHRSST observational data and $\mathbf{c}$ the mean SST anomaly 
anomaly north-east of the Faroe plateau $\left(\Delta T>0.6^{\circ} \mathrm{C}\right)$. The largest cold anomalies are relatively smaller $(\Delta T<$ $-0.3{ }^{\circ} \mathrm{C}$ ) and mainly towards the eastern boundary. We presume these warm/cold anomalous regions are due to our HYCOM boundary conditions which may be warmer/colder than they should be.

\subsubsection{Current Profiles}

We compare snapshot currents from our model and the HYCOM global ocean reanalysis (also used for our initialisation/boundary forcing) with current observations. Observational datasets were collected for BP plc and their partners by Fugro GEOS at two locations, Foinhaven (Foi) and Schiehallion (Sch), each at three depths. Current meter moorings and platform mounted Acoustic Doppler Current Profilers (ADCPs) were used to collect data over the period 17 September 1992 to 9 September 2007 (Foinhaven) and 21 September 1993 to 30 July 2007 (Schiehallion). Current datasets consist of 10-minute mean velocities. It was assumed that current data was fully screened for errors and spikes before archival in accordance with Fugro GEOS quality control.

Quantile-Quantile (Q-Q) plots are used to scatter the percentiles of different current speed datasets against each other, and so compare whether the two datasets have the same underlying distribution (Fig. 5). At both sites, HYCOM currents overestimate observational currents for the small and mid-range values, and underestimate the extremes. In comparison, the MITgcm model currents slightly underestimate the observations for small and midrange values but fit the extremes better than HYCOM. The MITgcm performs better than HYCOM at larger depths.

At the ADCP observational sites, current direction is mostly north-eastwards (Figs. 6 and 7). At Foinhaven, HYCOM currents are directed predominantly on a single bearing $\left(60^{\circ} \mathrm{T}\right)$ whereas the observations and our model have two main bearings $\left(30^{\circ} \mathrm{T}\right.$ and $\left.60^{\circ} \mathrm{T}\right)$. Also, the size of the speed bins (colours in Fig. 6) for our model match the observations better than for HYCOM. So the directional distribution of MITgcm currents are better than HYCOM-this may be due to the smaller grid spacing ( $2 \mathrm{~km}$ vs. $10 \mathrm{~km}$ ).
Fig. 5 Q-Q plots comparing speed distributions between our model and HYCOM with ADCP observations at two locations, Foinhaven $(\mathbf{a}, \mathbf{b})$ and Schiehallion (c, d), each with three depths: near-surface (blue), mid-depth (red) and $100 \mathrm{~m}$ above seabed (green)
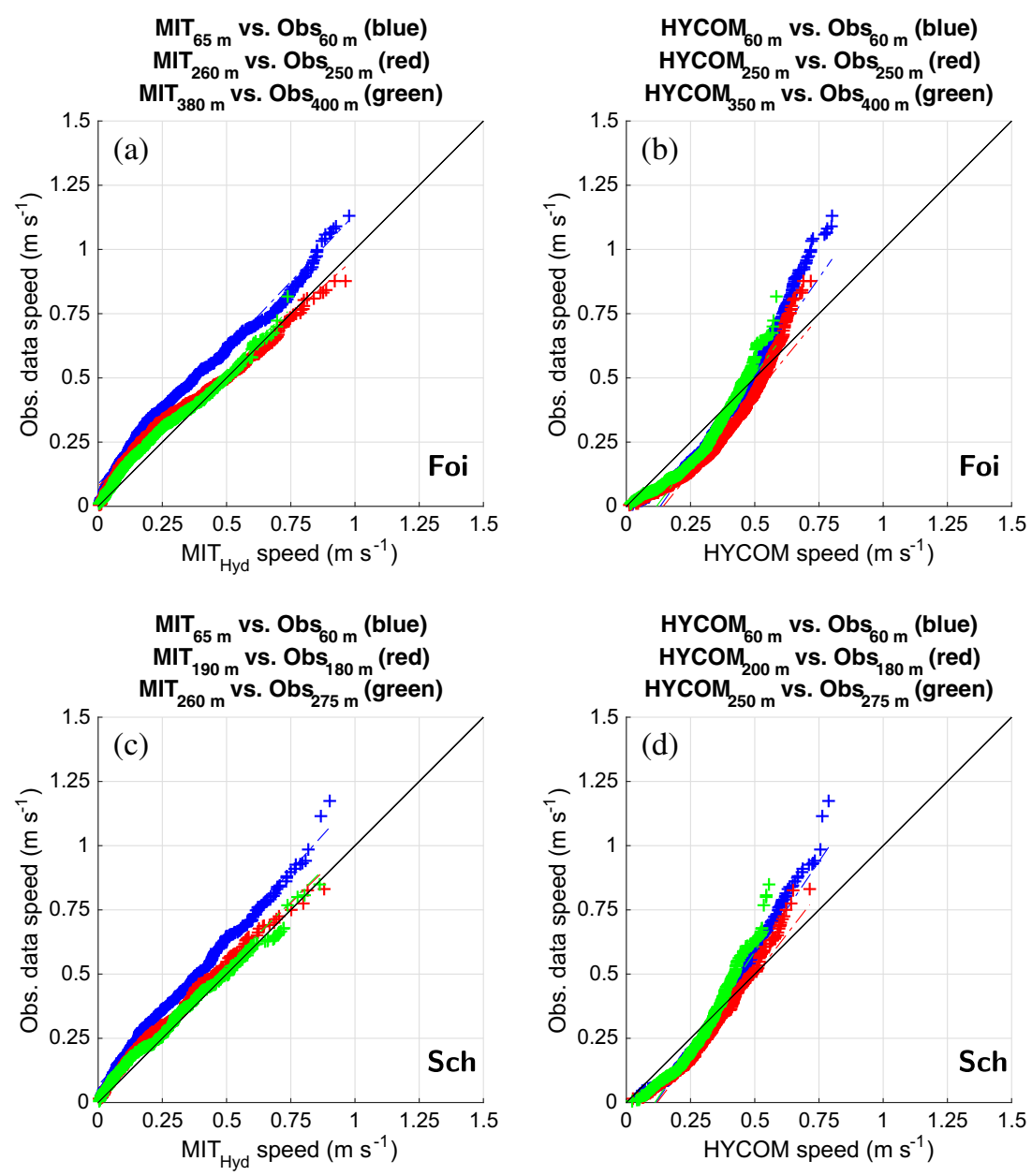
(a)

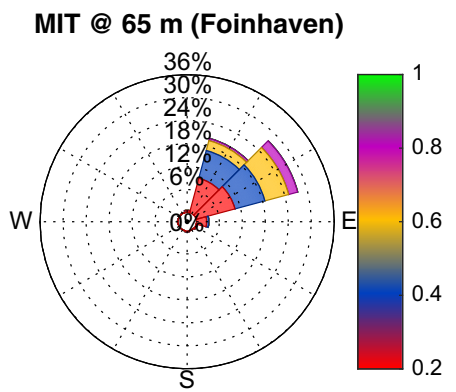

(b)

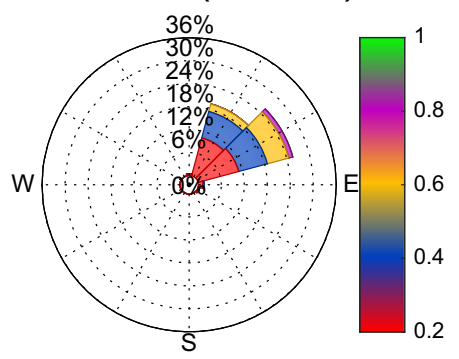

(c) MIT @ $380 \mathrm{~m}$ (Foinhaven)

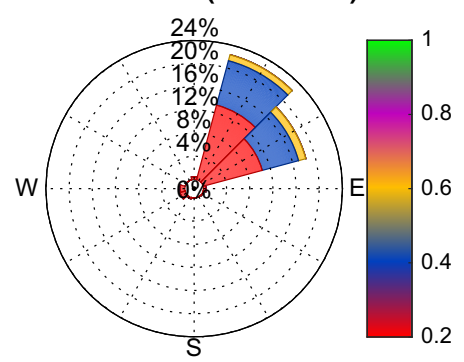

Obs. @ $60 \mathrm{~m}$ (Foinhaven)

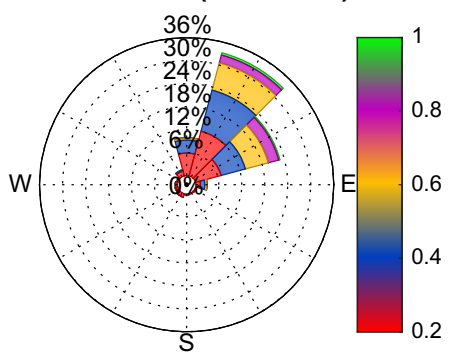

Obs. @ 250 m (Foinhaven)

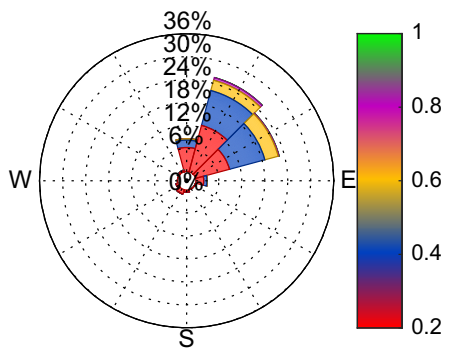

Obs. @ $\mathbf{4 0 0}$ m (Foinhaven)

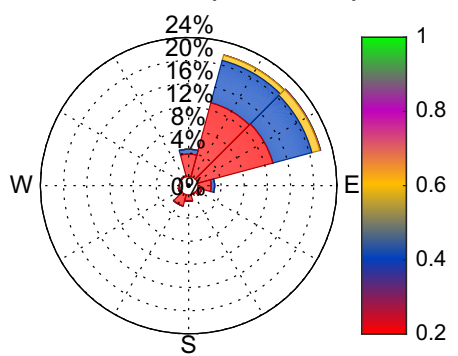

HYCOM @ 60 m (Foinhaven)

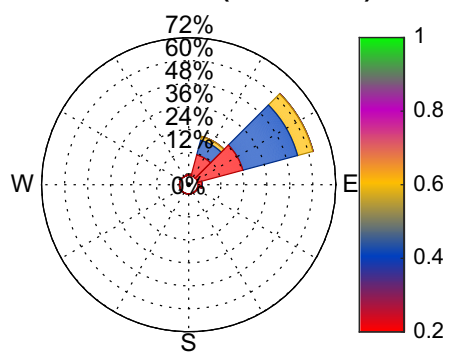

HYCOM @ 250 m (Foinhaven)

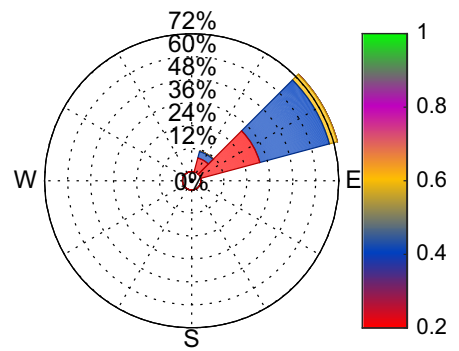

HYCOM @ 350 m (Foinhaven)

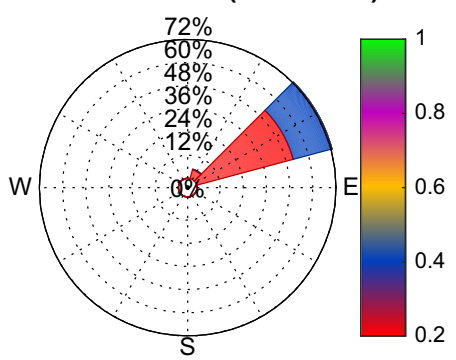

Fig. 6 Current-rose plots for model, observational and HYCOM currents for the Foinhaven site at the same depths as in Fig. 5. Twelve bins separate currents by direction and 5 bins further separate by speed (colours; units $\mathrm{m} \mathrm{s}^{-1}$ ). Colorbar values indicate the maximum speed in the coloured bin. Frequencies are indicated by percentages given on concentric circles. Note the larger frequencies on the HYCOM plots
At Schiehallion there is a clockwise bias of currents compared to observations, which is the same for HYCOM. We do not know why this is the case. Despite this bias, our speed distribution for each direction remains superior to HYCOM.

The temporal correlations of both HYCOM and MITgcm with observations was poor (not shown). We note that the observations are located near the slope where there is potential for baroclinic instability (Sherwin et al. 2006). Instabilities create random variability in currents, which are extremely difficult to capture in models and may explain why the correlations were poor.

\subsubsection{Hydrographic observations}

We present model data at the Fair-Isle Munken (FIM) cross-section and compare it against a 14-year mean climatology from Berx et al. (2013) (Fig. 8; for location of the cross-section see Fig. 1). We have not validated the Nolso-Flugga (NOL) cross-section as we do not have corresponding observations, but we show the results here for additional visualisation and context of the regional dynamics. Both FIM and NOL cross-sections show downwelling of isotherms towards the Scottish continental shelf (Fig. 8a, b). The largest temperatures $\left(T>10^{\circ} \mathrm{C}\right)$ are also found here. At FIM, a clear thermocline exists near $500 \mathrm{~m}$. However at NOL, the thermocline is less pronounced and the stratification is fairly uniform. Salinity profiles (Fig. 8c, d) show much weaker stratification of isohalines, especially towards the Faroe plateau. In near-surface and mid-depth, there is a meridional salinity gradient with fresher water towards the Faroe plateau and a high salinity core, indicative of the Continental Slope Current, located on the Scottish shelf. At greater depths, salinity is more uniform across the channel. 
(a)

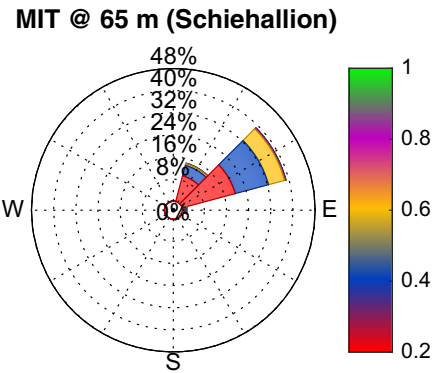

(b) MIT @ $190 \mathrm{~m}$ (Schiehallion)

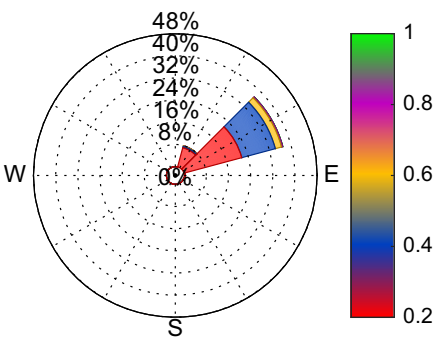

(c)

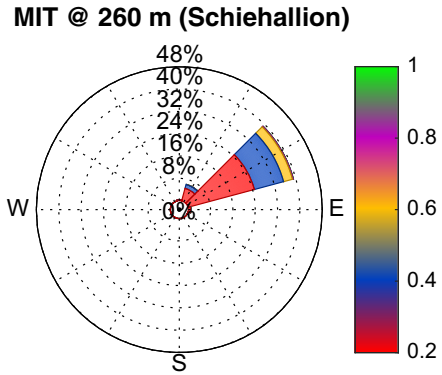

Obs. @ $60 \mathrm{~m}$ (Schiehallion)

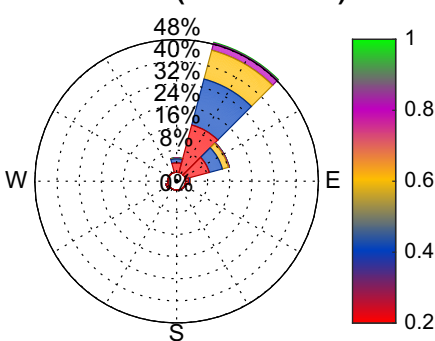

Obs. @ 180 m (Schiehallion)

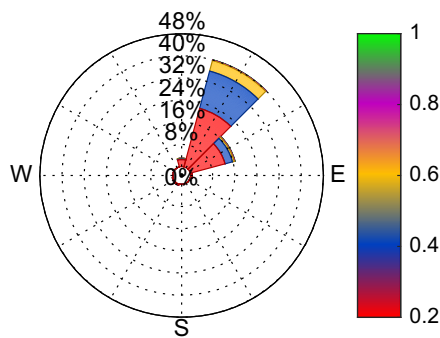

Obs. @ 275 m (Schiehallion)

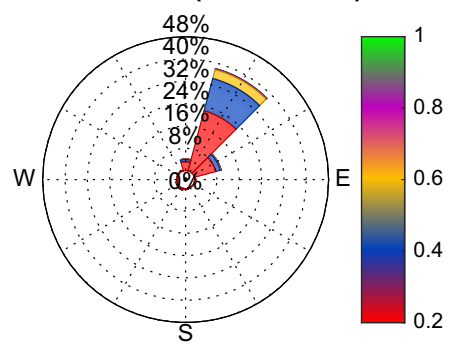

HYCOM @ 60 m (Schiehallion)

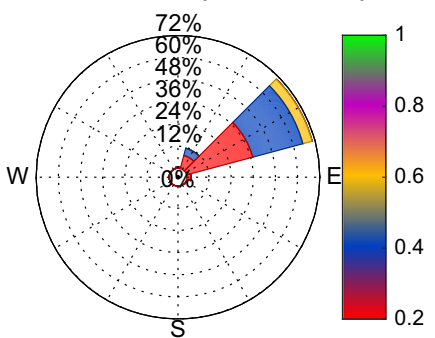

HYCOM @ 200 m (Schiehallion)

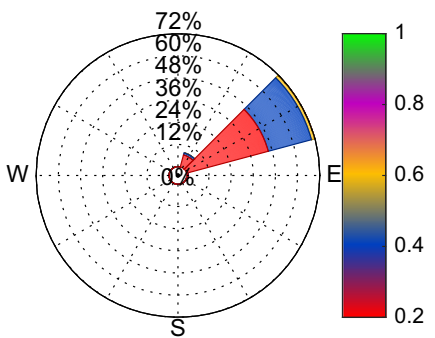

HYCOM @ 250 m (Schiehallion)

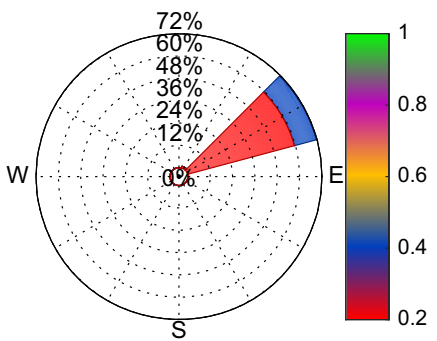

Fig. 7 As in Fig. 6 but for the Schiehallion site

We replicate the downwelling structure of isotherms well (Fig. 8a) compared to observations. The model matches the depth of the $5{ }^{\circ} \mathrm{C}$ isotherm (400 to $500 \mathrm{~m}$ ). For salinity, model isohaline structure is not as well-matched (Fig. 8c). In the model, there is a freshwater bias $(\Delta S \sim-0.1)$ in the upper $500 \mathrm{~m}$ and the absence of a clear halocline. We ascribe this bias to the HYCOM initial conditions, which are also too fresh in the upper layers compared to the observations (not shown). Our results on bottom fluxes (Section 3.2 onwards) should not be significantly affected by this bias.

Mean flow along the channel is marked by the presence of the slope current centred on the $500 \mathrm{~m}$ isobath (Fig. 9a, b). The largest slope current speeds (max. $>0.4 \mathrm{~m} \mathrm{~s}^{-1}$ ) are in the NOL section. Deep overflow waters do not reach as high speeds. Both sections also show a small south-westward return flow at depth and near the Faroe plateau. The acrosschannel mean circulation at FIM shows the slope current is directed towards the shelf $\left(<0 \mathrm{~m} \mathrm{~s}^{-1}\right)$ (Fig. 9c). At NOL its direction is away from the shelf $\left(>0.1 \mathrm{~m} \mathrm{~s}^{-1}\right)$.

Comparing Fig. 9a against mean along-slope currents from Berx et al. (2013), we have replicated the well-known high-speed slope current structure (see e.g. Hansen and Østerhus 2000). In the model, the $0 \mathrm{~m} \mathrm{~s}^{-1}$ delimiting contour extends too far north. Deep current structures support the results of Broadbridge and Toumi (2015) who reported a complex flow field at the bottom of the channel.

\subsubsection{Shelf-edge exchange}

From the model, the volume transport across the shelf-break (the shelf-break is defined as the $200 \mathrm{~m}$ isobath) is $3.7 \mathrm{~Sv}$ directed off-shelf. Averaging the volume transport quantity horizontally along the shelf (so dividing by the length of the shelf) gives a flux of $4.2 \mathrm{~m}^{2} \mathrm{~s}^{-1}$. Averaging this new quantity over the $200 \mathrm{~m}$ isobath (so dividing by $200 \mathrm{~m}$ ) gives $21 \times$ $10^{-3} \mathrm{~m} \mathrm{~s}^{-1}$; this value is equivalent to the average off-shelf velocity for all model grid cells.

Burrows and Thorpe (1999; Table 4) estimate the acrossshelf mass flux to be $-10 \times 10^{-3} \mathrm{~m} \mathrm{~s}^{-1}$ (summer) and $15 \times 10^{-3} \mathrm{~m} \mathrm{~s}^{-1}$ (winter) over $200 \mathrm{~m}$; so combined it is off-shelf, about $5 \times 10^{-3} \mathrm{~m} \mathrm{~s}^{-1}$. There is large uncertainty on the summer estimate as only one drifter crossed 

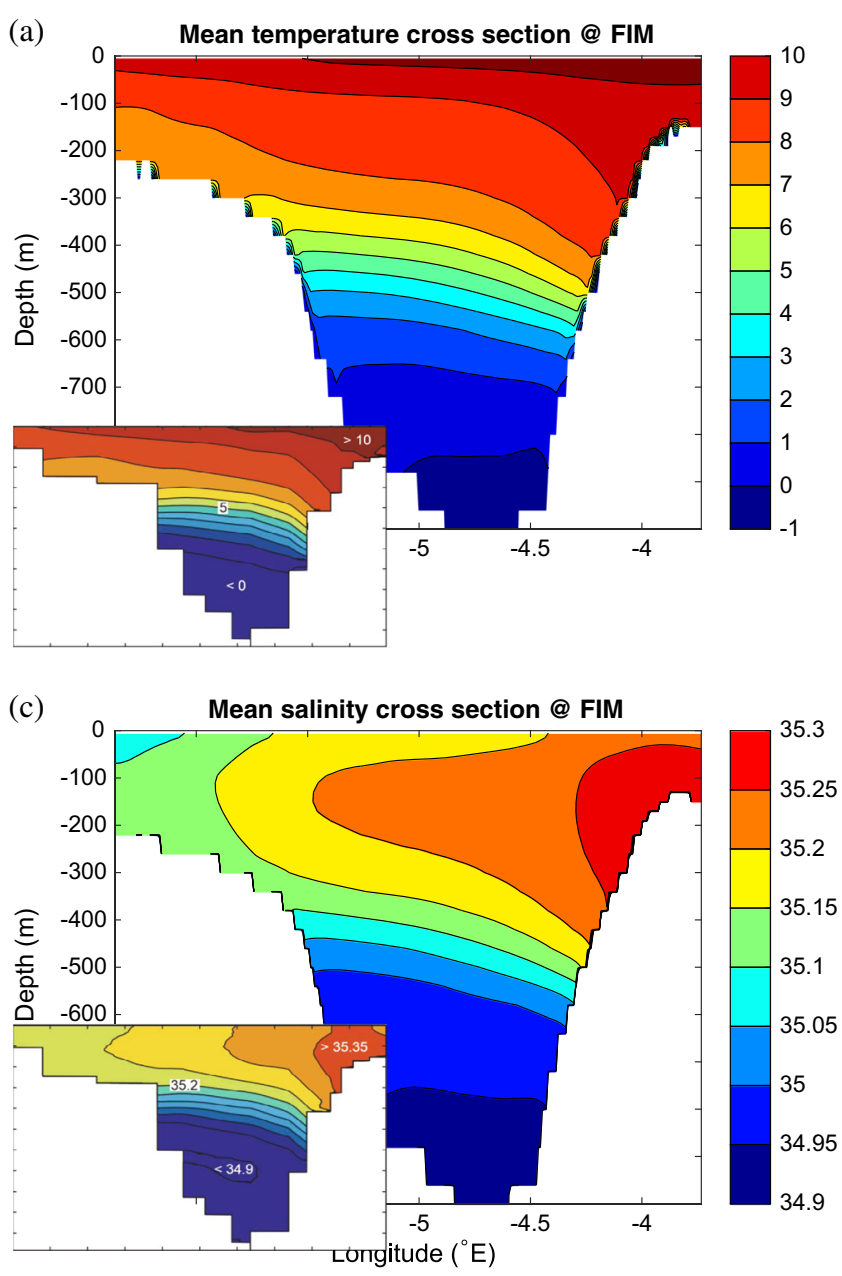

Fig. 8 Mean (2003-2006) temperature (a, b) and salinity (c, d) data for the Fair-Isle Munken (FIM) and Nolsa-Flugga (NOL) crosssections. For the FIM section, temperature (inset, a) and salinity

the $200 \mathrm{~m}$ isobath. Huthnance (1995) estimate the same quantity to be 6 to $7 \mathrm{~m}^{2} \mathrm{~s}^{-1}$ over $500 \mathrm{~m}$, or $12 \times 10^{-3}$ to $14 \times 10^{-3} \mathrm{~m} \mathrm{~s}^{-1}$ vertically averaged. Turrell et al. (1992) used a single current mooring near the $200 \mathrm{~m}$ shelf-edge, and found for a 3-month summer period the across-shelf current was on-shelf at both $30 \mathrm{~m}$ and $187 \mathrm{~m}\left(-25 \times 10^{-3} \mathrm{~m}\right.$ $\mathrm{s}^{-1}$ and $-6 \times 10^{-3} \mathrm{~m} \mathrm{~s}^{-1}$ ). They defined the slope current direction inferring bathymetry from Admiralty charts. Comparing the previous vertically averaged estimates with our higher resolution estimate $\left(21 \times 10^{-3} \mathrm{~m} \mathrm{~s}^{-1}\right)$, we have offshelf transport though it is not unreasonable given the large uncertainty and sparsity of observations.

\subsection{BBL veering}

Is the slope current topographically locked to the bathymetry? We can answer this by considering the difference between $\theta_{s}^{T P T}$ and $\theta_{s}^{L G}$ orientations (Section 2.2;

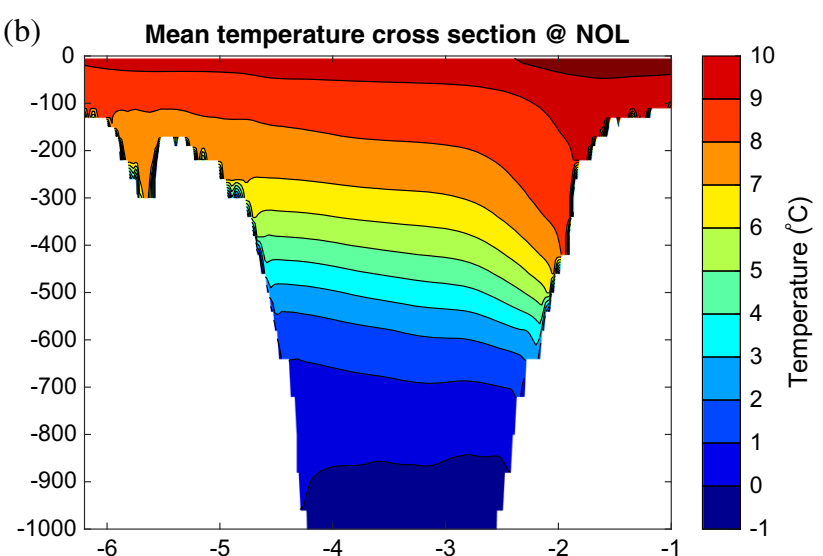

(d)

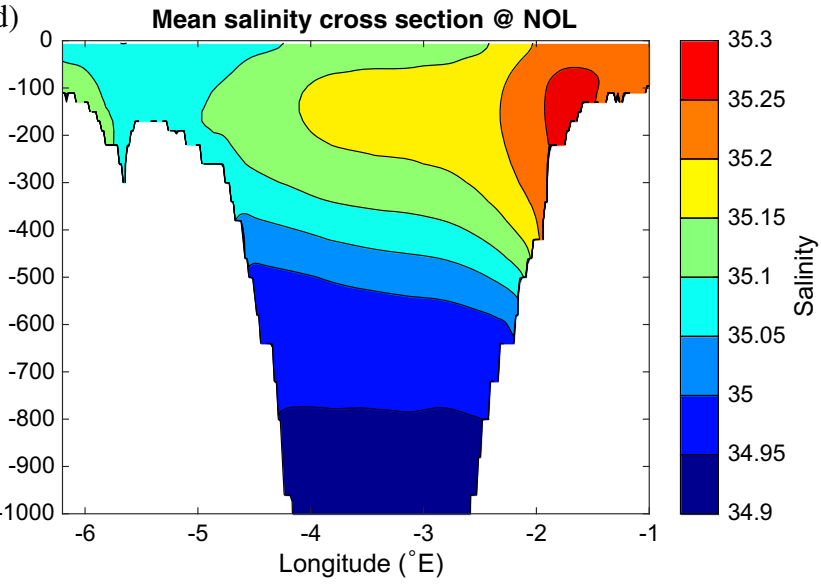

climatologies (inset, c) provided by Berx et al. (2013) are used for validation: note the depths are the same as the model and the colour schemes match for (a) but not for (c)

recall $\theta_{s}^{T P T}$ is defined from the time-averaged interior current direction whereas $\theta_{s}^{L G}$ is defined from bathymetric data). The shelf-averaged difference of $\theta_{s}^{T P T}-\theta_{s}^{L G}$ is $(5 \pm 32)^{\circ}$. This is significantly greater than $0(p<$ 0.01 , 1-tailed $t$-test; $99 \%$ CI 2 to $\left.9^{\circ}\right)$. So on average, along the shelf, the interior current is not topographically locked but directed slightly off-shelf. This indicates the mean-flow is important to understanding the BBL fluxes.

Are BBL currents also directed off-shelf? $\left\langle\theta_{\text {veer }}^{L G}\right\rangle$ is the time-mean veering of currents in the BBL with respect to the $\theta_{s}^{L G}$ orientation ( $\mathbf{V}_{\mathbf{B B L}}$ in Fig. 2). Averaged along the shelf, $\left\langle\theta_{\text {veer }}^{L G}\right\rangle$ is $(14 \pm 33)^{\circ}$. This is statistically greater than $0\left(p<0.01,1\right.$-tailed $t$-test; $99 \%$ CI 10 to $\left.18^{\circ}\right)$. So on average the BBL currents are directed off-shelf (as is the interior slope current).

However, do the BBL currents veer with respect to the interior current, potentially due to Ekman dynamics? Under 

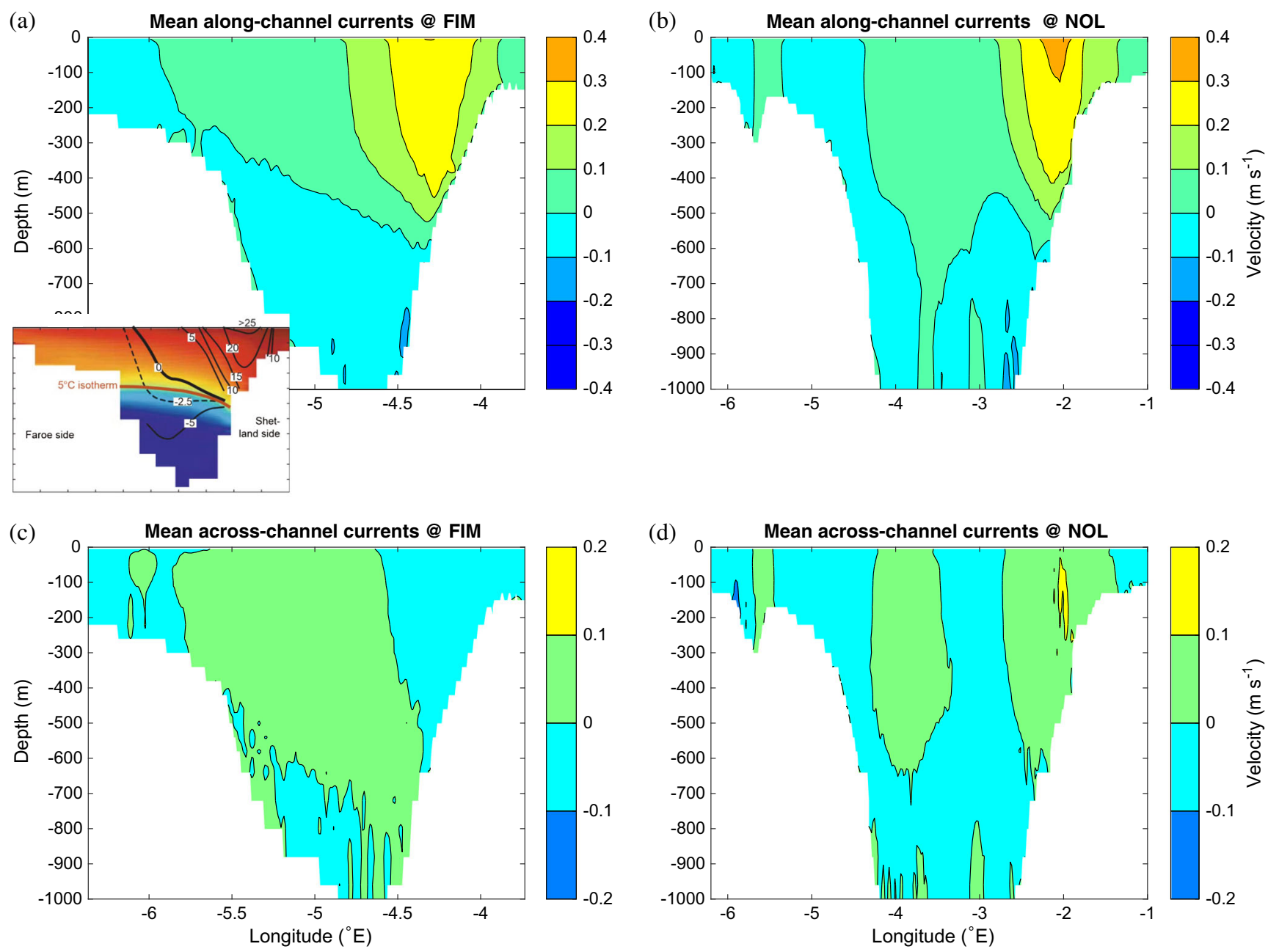

Fig. 9 Mean (2003-2006) model currents for the Fair-Isle Munken (FIM) and Nolsa-Flugga (NOL) cross-sections. The currents were rotated along- (a, b) and across- (c, d) channel, so velocities are positive north-east and north-west respectively. For the FIM section this rotation was by a bearing of $38^{\circ} \mathrm{T}$ as in Berx et al. (2013).

Additionally, along-channel currents (inset, a) provided by Berx et al. (2013) are used for validation (the depth scale is the same as our results, colour $=$ temperature and dashed/solid contours $=$ velocity). For the NOL section, currents were rotated perpendicular/parallel to the cross-section (see Fig. 1)

theoretical assumptions (e.g. constant flow field) the integrated transport in a bottom Ekman layer would be directed $90^{\circ}$ left of the mean-flow (Northern Hemisphere). Now $\left\langle\theta_{\text {veer }}^{T P T}\right\rangle$ is the time-mean veering of currents in the BBL with respect to the $\theta_{s}^{T P T}$ orientation. Averaged along the shelf, $\left\langle\theta_{\text {veer }}^{T P T}\right\rangle$ is $(9 \pm 8)^{\circ}$ respectively. Though this result is not a $90^{\circ}$ veering (as would be the case for a theoretical Ekman layer) it is nonetheless significantly greater than $0\left(p<0.01,1\right.$-tailed $t$ test; $99 \%$ CI 8 to $\left.10^{\circ}\right)$. So on average the BBL currents additionally veer off-shelf with respect to the interior current (which we presume is due to Ekman dynamics and aim to show in later sections). This indicates towards BBL fluxes being a combination of both mean-flow and Ekman dynamics, with the latter in spite of highly non-idealised conditions.

\subsection{Seasonal variation of the BBL fluxes}

We integrated the model BBL volume transport along the shelf (i.e. $\sum V_{B B L} \times h_{B B L} \times L$; where $L$ is the mid-point distance between stations) into a time-series to investigate its monthly variation (Fig. 10). This shelf-integrated volume transport was also calculated for both orientations $\left(\theta_{s}^{L G}\right.$ and $\left.\theta_{s}^{T P T}\right)$. Both orientations show similar sinusoidal variability though the $\theta_{s}^{T P T}$ has a smaller transport (by about $0.1 \mathrm{~Sv}$ ) compared to $\theta_{s}^{L G}$. There is a seasonality to the BBL volume transport, with a maximum in March and a minimum in August. The BBL transport is high $(>0.6 \mathrm{~Sv})$ in the winter (Dec-Jan-Feb) and March. There is a rapid decrease in the latter spring months, to the lowest annual levels in summer $(\sim 0.4 \mathrm{~Sv})$. In September, the transport 
Fig. 10 A composite time-series (2003-2006) of monthly shelf-integrated BBL transport from the model. The BBL (solid), Ekman (dashed) and mean-flow $V_{\text {int }}$ (dash-dot) transports are calculated for both the $\theta_{s}^{L G}$ (blue) and $\theta_{s}^{T P T}$ orientations (red)

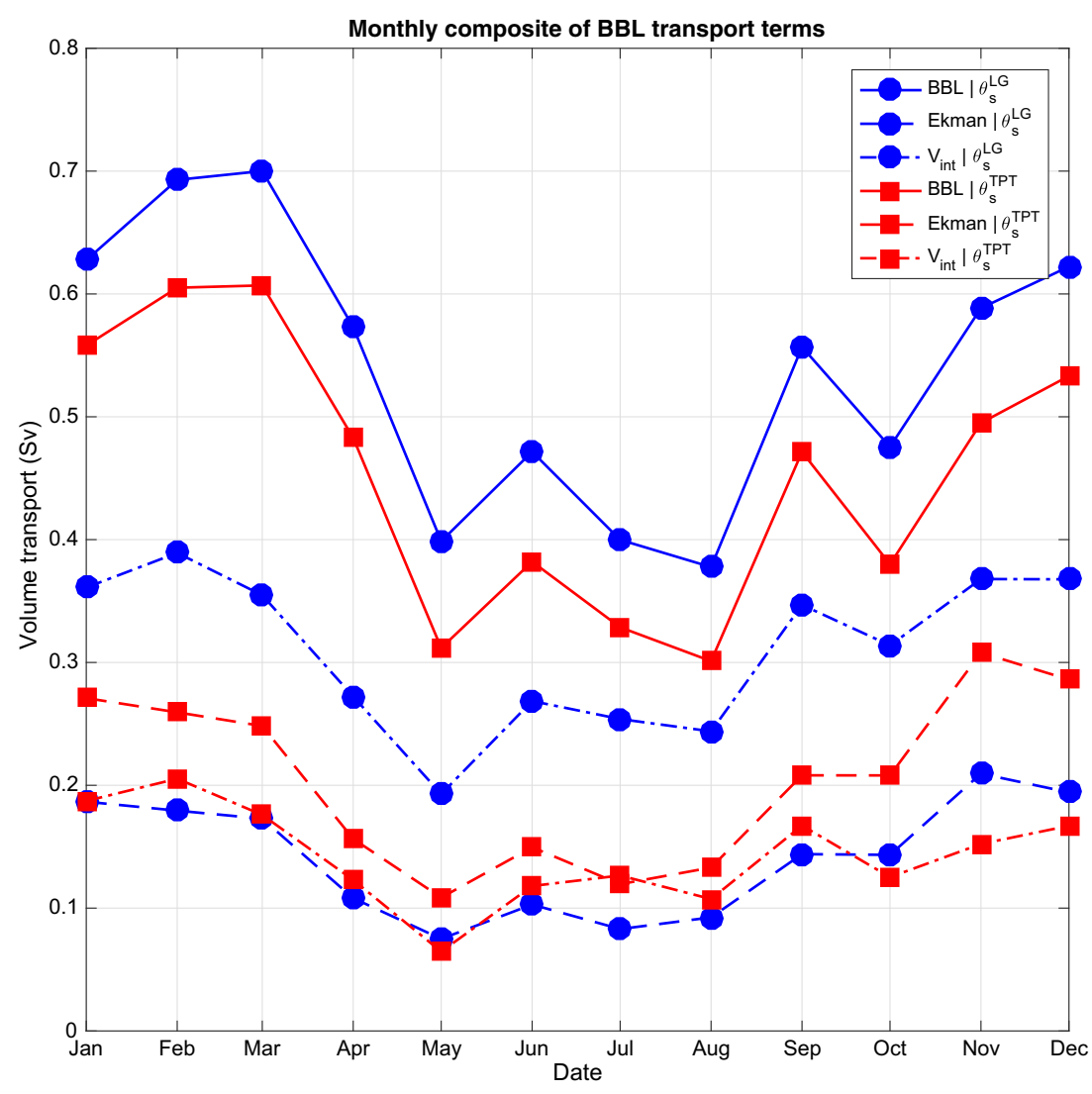

rapidly increases to the high winter levels. There are deviations from this general trend in June/October which have higher/lower transports when compared to their respective seasons.

In the following sections, we will decompose the BBL flux variability into the interior current speed (i.e. the Ekman term) and direction (i.e. on-/off-shelf given by $V_{i n t}$ ), and in doing so connect and quantify the seasonal variability of the BBL fluxes to the interior slope current dynamics. For now, an initial decomposition of the BBL transport into Ekman plus mean-flow transport (Fig. 10) shows a seasonality for both terms (irrespective of orientation), matching the seasonality of the BBL transport. The contribution of the mean-flow compared to the Ekman-transport is greater when using the $\theta_{s}^{L G}$ rather than the $\theta_{s}^{T P T}$ orientation. This is because the $\theta_{s}^{T P T}$ orientation is calculated from the timeaveraged direction of the interior flow $\left(\theta_{s}^{T P T}=\left\langle\theta^{T P T}\right\rangle\right.$ from Fig. 2). This results in some of the across-slope transport being absorbed into the definition of the TPT slope angle, that otherwise would have been ascribed to the mean-flow in the LG case.

\subsection{Local fluxes}

\subsubsection{Ekman flux}

The basic Ekman-drain model linearly relates the acrossslope BBL flux with the Ekman flux. Scatter plots between these fluxes show large variability with $R^{2}$ of about 0.3 and 0.1 for two locations (Fig. 11). There is similar correlation when the bottom stress is parameterised as either a quadratic or a linear function of the interior current.

For the shelf-mean, the correlation is also similar for linear or quadratic formulation $\left(R^{2}=0.27[0.08,0.43]\right.$ and $0.25[0.09,0.40]$ respectively). By definition, the Ekmandrain model should have zero intercept. We find that the shelf-mean $C$ (intercept) for the linear drag is $(0.07 \pm$ $0.48) \mathrm{m}^{2} \mathrm{~s}^{-1}$ and for the quadratic drag it is $(0.30 \pm$ $0.55) \mathrm{m}^{2} \mathrm{~s}^{-1}$. Shelf-mean intercepts for the linear/quadratic drag are significantly different from 0 , and also from each other ( $p<0.01$; two-tailed $t$ test). We proceed with the quadratic drag as this parameterisation is used in the simulation (and has an explicit drag coefficient we can use for 

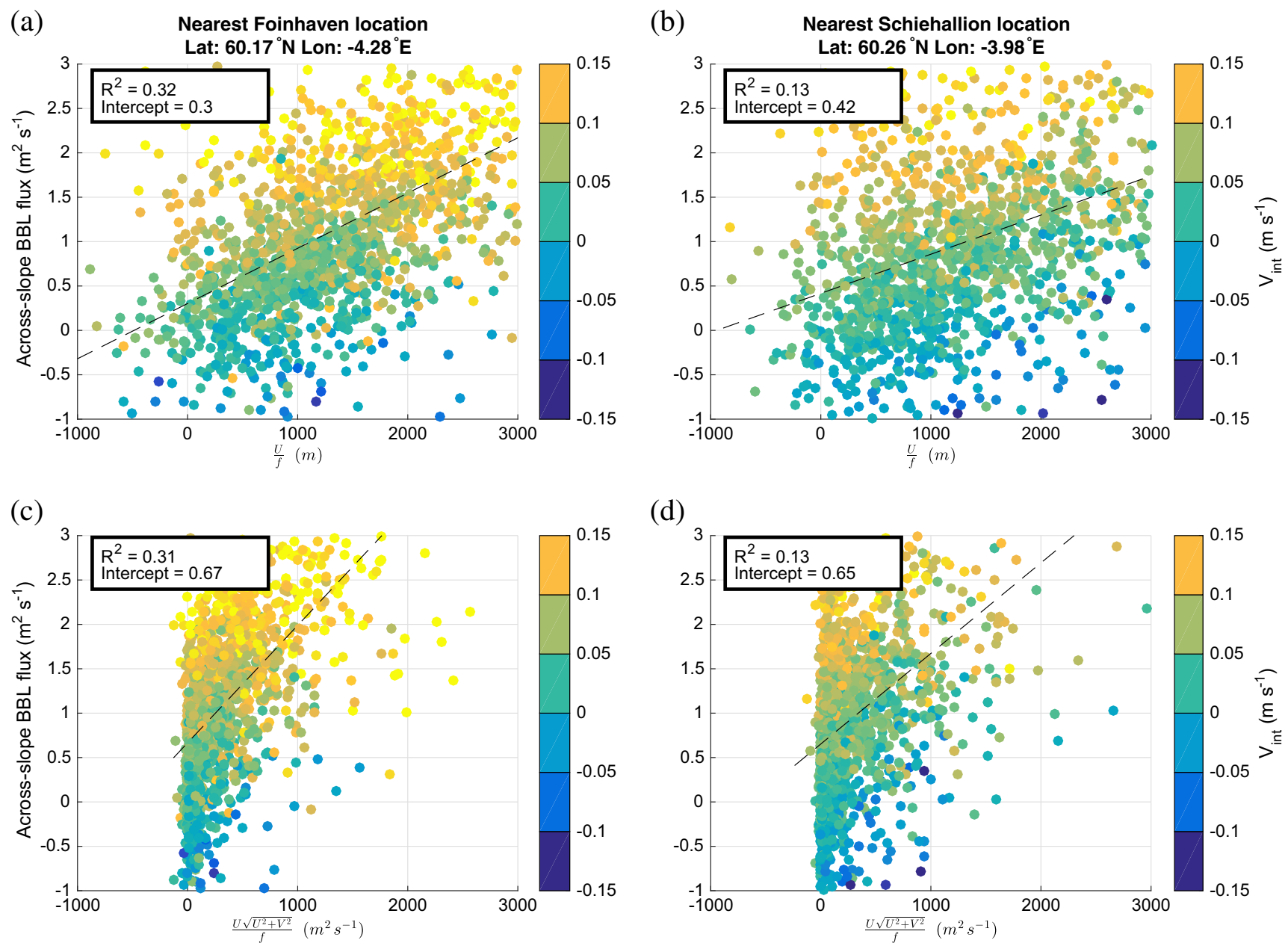

Fig. 11 Fluxes are calculated with a linear $(\mathbf{a}, \mathbf{b})$ or quadratic $(\mathbf{c}, \mathbf{d})$ drag for the locations closest to our ADCP observations. These are chosen for consistency with validation. Scatter markers are coloured by the across-slope component of the interior velocity, $V_{\text {int }}$. The line of best fit is also provided for reference

consistency; see Eq. 3). Overall, the low shelf-mean $R^{2}$ indicates that the basic Ekman-drain model does not explain much of the variability in the across-slope BBL flux.

\subsubsection{Variation of the BBLflux with the interior current}

To try and improve the basic Ekman-drain model, we first investigate the variation around the best fit (Fig. 11), and see if it can be explained by the across-slope component of the interior current, $V_{i n t}$. Points above/below the line of best fit (i.e. residuals of the Ekman-drain regression fit) are frequently associated with the interior current directed off/on-slope. A method of examining this for all the locations is outlined: a regression line is fitted between across-slope BBL and calculated Ekman fluxes, but for the data subset where $V_{i n t}=0$. We count when a point above (or below) this line is also a point when $V_{\text {int }}$ is greater (or less) than zero. If $V_{i n t}$ is not related to the residual, we would expect this condition to be satisfied $50 \%$ of the time. Averaged along the shelf, the percentage of time when this condition is satisfied is $(84 \pm 10) \%$ (here the error is between shelf locations, not in time). This is significantly greater than $50 \%$ ( $p<0.01$; one-tailed $t$ test). This indicates that locations do have an additional transport, due to $V_{\text {int }}$, from that predicted by the simple Ekman-drain model. So additional offshore/onshore fluxes are associated with an offshore $\left(V_{i n t}>0\right) /$ onshore $\left(V_{i n t}<0\right)$ interior flow.

\subsubsection{The across-slope interior current, $V_{\text {int }}$}

Analogous to Section 3.4.1, we also investigate an interior current-only model relating the across-slope BBL flux and 
$V_{\text {int }}$ where we find a shelf-mean $R^{2}=0.68[0.58,0.84]$ (not shown). These shelf-mean correlations are significantly higher $(p<0.01$; 1-tailed $t$-test $)$ than in the case of Ekman-only flux (Section 3.4.1).

\subsubsection{Multivariate regression of the BBL flux without wind}

To further probe the relationships between the across-slope BBL, Ekman and $V_{i n t}$ fluxes, we perform a multivariate linear regression (5), using the quadratic drag formulation.

The Ekman flux and $V_{i n t}$ are effectively independent from each other based on an analysis of Pearson's $r: 75 \%$ of locations are significantly independent $(p<0.01)$, with their observed $t$-statistic $\left(t_{o b s}=r \sqrt{\frac{d f-2}{1-r^{2}}}\right)$ smaller than the estimated $t$-statistic. For correlation, the estimated $t$-statistic threshold is equivalent to an $|r|>0.06$ because of the large sample size, and the shelf-mean $r=0.26[0.07,0.54]$. As such, for the locations with statistical 'significance' of correlation, the $r$-values are poor in general and do not equate to practical significance.

Figure 11 shows that much more of the variability in the BBL flux can be explained by using multiple regression. At the two sites the $R^{2}$ values improve from about 0.3 and 0.1 , to 0.8 and 0.6 , respectively (Fig. 12). The intercept at Foinhaven is much lower than in the Ekman-only model but this is not the case at Schiehallion, where the value is similar. There still remains some residual variability despite the improvement.

The shelf-mean $R^{2}=0.75[0.66,0.87]$ for the multivariate model. The distribution of $R^{2}$ in the multivariate case is significantly greater ( $p<0.01 ; 2$-sample $K-S$ test) than in either single variable models (Ekman-only $R^{2}=0.25$, $V_{\text {int }}$-only $\left.R^{2}=0.68\right)$. Improvements to the Ekman-only model (Section 3.4.1) are made at over $98 \%$ of locations along the shelf when $V_{i n t}$ is included as a variable in the multi-regressive model. The median ratio of mean$V_{i n t}$ to mean-Ekman fluxes in the multivariate model is
$2.2[1.1,4.8]$, demonstrating that the mean-flow contributes about twice as much as the Ekman flux to the across-slope BBL flux.

We additionally repeated our multivariate regression at the $400 \mathrm{~m}$ isobath (taking a $40 \mathrm{~m}$ BBL layer with a $120 \mathrm{~m}$ interior current layer above this). The multivariate model shelf-mean $R^{2}=0.50[0.41,0.60]$, compared to Ekman- and $V_{\text {int }}$-only models with shelf-mean $R^{2}=$ $0.29[0.14,0.43]$ and $0.43[0.31,0.57]$ respectively. The multivariate model shelf-mean $R^{2}$ is a significant improvement over both univariate models $(p<0.01$; 2-sample $K-S$ test), though smaller than the multivariate model at $200 \mathrm{~m}$ $\left(R^{2}=0.75\right)$.

We have shown that for individual locations at the $200 \mathrm{~m}$ and $400 \mathrm{~m}$ isobath the BBL fluxes can be better explained as the sum of an Ekman flux plus mean-flow flux (by the improvement of the multivariate model $R^{2}$ over the univariate model $R^{2}$ ). Though we have explained much of the observed temporal variability of BBL fluxes, we do not claim that this regression model can be used as an effective predictor model. This is because the coefficients in the multivariate regression model of Eq. 5 have high spatial variability (not shown). The $\Gamma$ (Ekman) coefficient distribution is nearly symmetrical about a mean $0.46[0.27,0.63]$. The $\alpha\left(V_{\text {int }}\right)$ coefficient distribution is positively skewed, with a modal value between $18 \mathrm{~m}$ and $19 \mathrm{~m}$, with mean $13.8[10.6,17.9] \mathrm{m}$. The $C$ (intercept) distribution has mean $(0.15 \pm 0.2) \mathrm{m}^{2} \mathrm{~s}^{-1}$, which is significantly lower than in the quadratic drag Ekman-only case $\left(0.30 \mathrm{~m}^{2} \mathrm{~s}^{-1}\right.$; Section 3.4.1), though still not significantly different from zero ( $p<0.01$, two-tailed $t$ test).

\subsubsection{Multivariate regression of the BBL flux with wind}

The domain mean winds are predominantly westerly and so are downwelling favourable (Fig. 13). This may potentially drive a 2-D downwelling circulation affecting the variability of BBL fluxes. We tested whether wind-driven surface
Fig. 12 Regression plots of across-slope BBL flux against Ekman $+V_{\text {int }}$ fluxes (5) for the same sites as in Fig. 11. The line of best fit is provided for reference
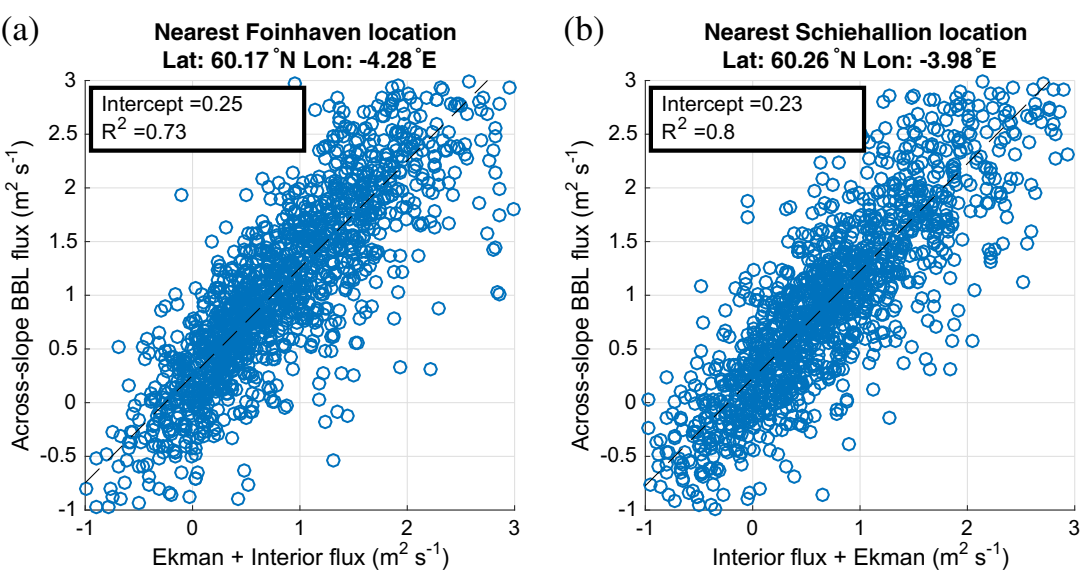


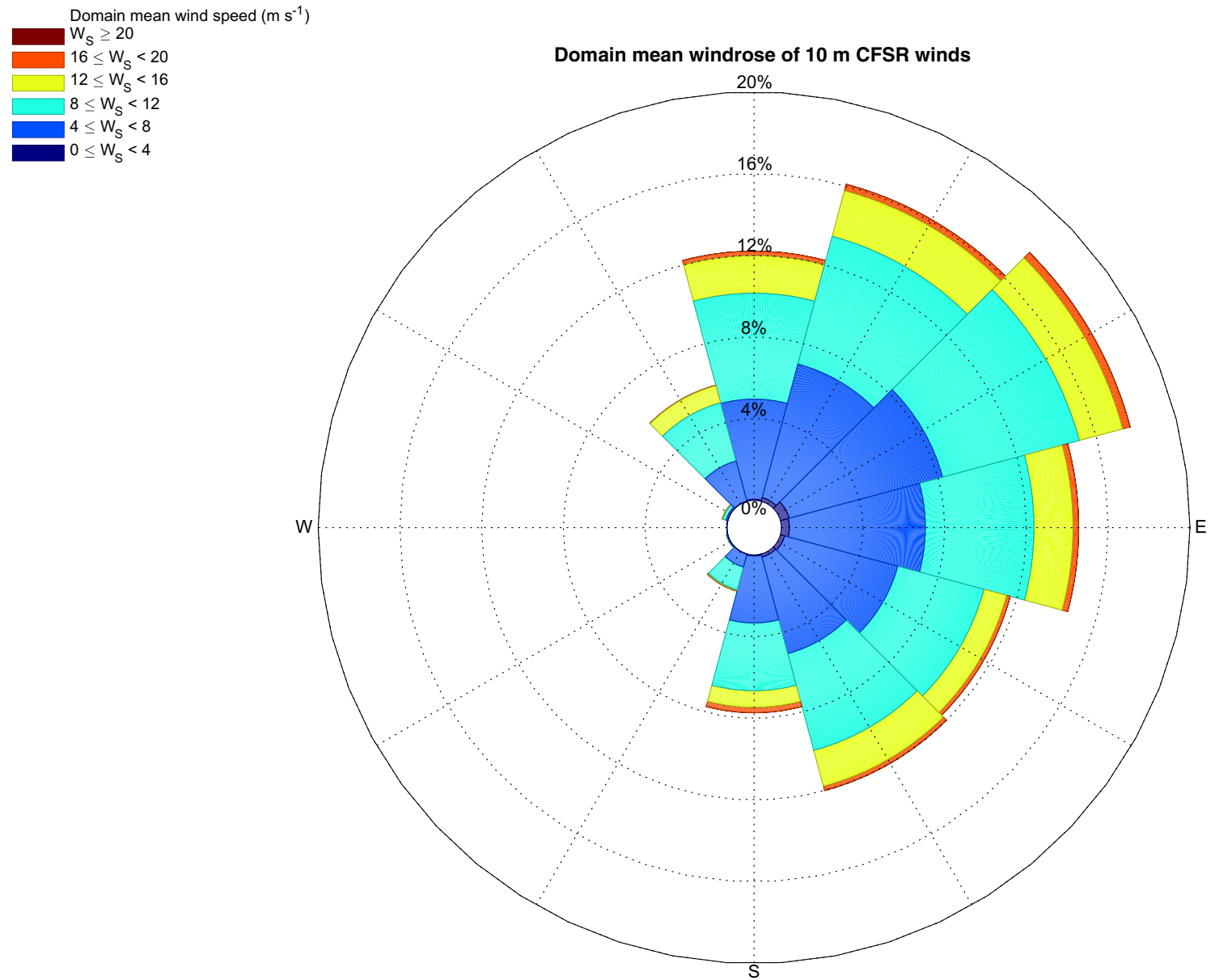

Fig. 13 Domain mean CFSR windrose

Ekman transport, $Q_{W}^{\perp}$, would contribute to the BBL flux by the addition of this term to our existing regression model (Section 2.4). For the $200 \mathrm{~m}$ isobath we found the shelfmean $R^{2}=0.75[0.66,0.87]$ with the intercept $C=(0.15 \pm$ $0.20) \mathrm{m}^{2} \mathrm{~s}^{-1}$. There is no change in the parameters, and the goodness of fit is not significantly different from the nowind multivariate regression model of Eq. 5. This was also true at the $400 \mathrm{~m}$ isobath. Thus, we neglect the addition of a 2-D wind-forced downwelling term in our model and reject it as a candidate explanation for variability of BBL fluxes.

\subsection{Shelf integrated volume transport}

Estimates of the shelf-integrated volume transports of the terms from the multivariate regression of Eq. 5 (BBL, Ekman and $V_{\text {int }}$ ), as a function of the time-averaging of the currents, are all positive/off-shelf (Fig. 14a). For the $\theta_{s}^{L G}$ orientation when currents are averaged over multiple days, the $V_{\text {int }} /$ Ekman transport increase/decrease with averaging but the total BBL transport remains constant. For the $\theta_{s}^{L G}$ orientation when currents are averaged daily, the BBL transport is $0.53 \mathrm{~Sv}$ and the contribution from the Ekman and $V_{\text {int }}$ flux is $0.15 \mathrm{~Sv}$ and $0.31 \mathrm{~Sv}$ (so $V_{i n t}$ approximately double). Applying our multivariate regression model (Section 2.4) to the shelf-integrated transports calculated after daily current averaging, the model $R^{2}=0.91$. We also considered the addition of a shelf-integrated wind-driven Ekman term (c.f. Section 3.4.5) where we found that the wind was not a contributing factor to the shelf-integrated BBL transport (not shown).

The BBL transport for the $\theta_{s}^{T P T}$ orientation is $0.45 \mathrm{~Sv}$. The Ekman and $V_{i n t}$ fluxes are $0.20 \mathrm{~Sv}$ and $0.14 \mathrm{~Sv}$ respectively (Ekman approximately 1.5 times larger). It may appear contradictory that there is a mean-flow contribution in the TPT case, given that the TPT slope angle is calculated from the time-mean angle (recall $\theta_{S}^{T P T}=\left\langle\theta^{T P T}\right\rangle$; see Fig. 2). This apparent contradiction can be resolved by noting that the magnitude of $\mathbf{V}_{\text {int }}$ can change without a change in direction. Therefore, in the TPT case, when integrating the fluxes over time, there can be a non-zero net $V_{i n t}$ transport. Only in the limiting case where all the off-shelf flow is equal in magnitude to the on-shelf flow will there be no net 
Volume transports for global coefficient mode

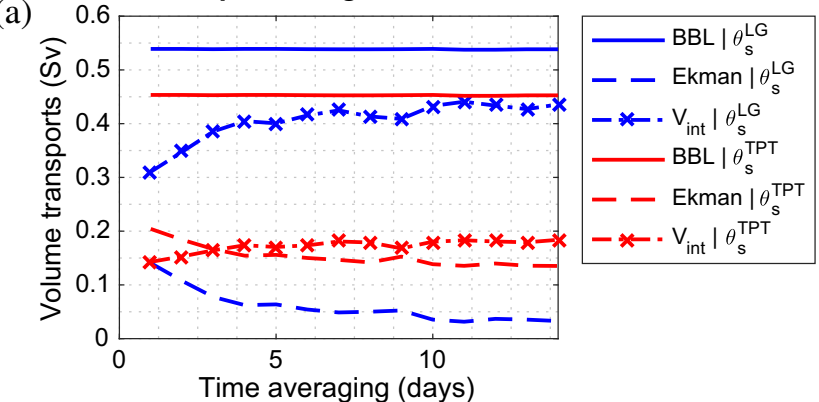

Ratio of $V_{\text {int }}$ to Ekman transports for global coefficient model

(b)

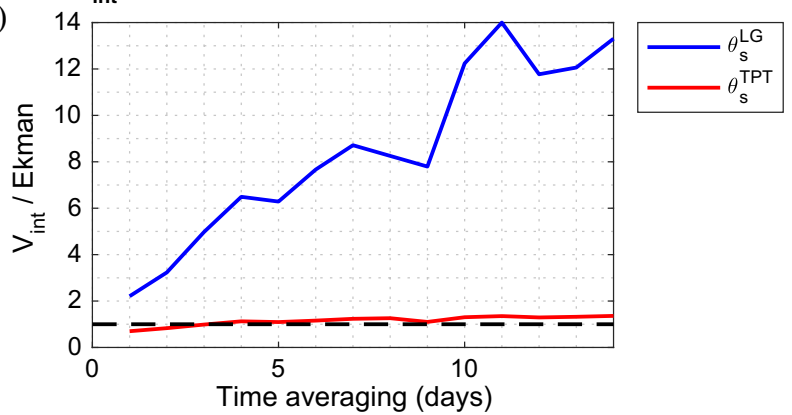

Fig. 14 a Shelf-integrated volume transport of the terms in the multivariate regression model (5): the across-slope BBL transport (solid), the Ekman term (dashed) and the $V_{\text {int }}$ term (dash-x). Colours differentiate which $\theta_{s}$ orientation was used. b The ratio of $V_{\text {int }}$ to Ekman terms from (a), for both orientations, with a constant reference line of unity plotted

$V_{\text {int }}$ transport. Our result of non-zero $V_{i n t}$ transport in the TPT case therefore means that the off-shelf flow is stronger than the on-shelf flow. That being said, using the TPT orientation does cause the net $V_{i n t}$ and BBL transports to be smaller than in the LG case. This is because in calculating $\theta_{s}^{T P T}$ some of the across-shelf transport, that would be present in the LG case, is absorbed.

The ratio of $V_{\text {int }}$ to Ekman terms in the multivariate regression is above 2 for daily averages but increases over 10 for longer time averages (Fig. 14b). The difference in orientation method is stark: compared to the $\theta_{S}^{L G}$ orientation, $\theta_{s}^{T P T}$ has nearly even ratios (for current averaging $\geq 4$ days the $V_{\text {int }}$ term begins to dominate over the Ekman term but not to the same scale as for $\theta_{s}^{L G}$ ). In short, for the $\theta_{s}^{L G}$ orientation the $V_{i n t}$ term is dominant over the Ekman term, however for the $\theta_{S}^{T P T}$ orientation the Ekman contribution is more pronounced and nearly equal to $V_{i n t}$ contribution.

\subsection{Decorrelation length scale}

The decorrelation length scales of the transports were determined using two different methods (Section 2.5). The $e$ folding distance of $r$ (the mean correlation coefficient per bin) for Ekman transport is approximately $80 \mathrm{~km}$ and near-grid $(\sim 5 \mathrm{~km})$ scale for BBL and $V_{\text {int }}$ (Fig. 15). There is a strong similarity between BBL and $V_{i n t}$ decorrelation. The standard errors are sufficiently small so that the decorrelation scale of the fluxes (Ekman and $V_{i n t}$ ) are significantly different. However, to one standard deviation, the variability in $e$-folding distance is large: from $\sim 5 \mathrm{~km}$ to over $200 \mathrm{~km}$ for the Ekman flux, and from sub-grid scale to over $50 \mathrm{~km}$ for $V_{\text {int }}$. The decorrelation length of $\epsilon$ (the residual flux in the regression model) is very small (on the order of grid spacing).

The second method of determining the decorrelation length scale for Ekman transport (Section 2.5) shows the normalised RMSD grows rapidly with distance to 1.0 at $90 \mathrm{~km}$ and then slowly rises. We therefore take the distance over this rapid growth as the decorrelation length scale, approximately $90 \mathrm{~km}$. As this is the same order of magnitude as the first method, we use it as a confirmation of the result from the previous method, i.e. the Ekman transport has a decorrelation length scale of about $80 \mathrm{~km}$. The gridscale spatial variability in across-slope BBL transport is due to the mean-flow.

\section{Discussion}

The major motivation for this study was to investigate the variability, magnitude and spatial scale of across-slope BBL transport along the Shetland shelf. Concerning shortterm variability, a previous hypothesis (Souza et al. 2001; Simpson and McCandliss 2013) of an Ekman-drain model only partly explains the bottom boundary layer fluxes. We used a regression method to decompose the daily $\mathrm{BBL}$ transport into different physically based components. We introduce a multivariate regression model of the BBL transport (5) as a linear combination of the Ekman flux and a mean-flow flux (the across-slope component of the interior flow). Adjusted- $R^{2}$ in the multivariate model is higher than in either the Ekman-only or $V_{\text {int }}$-only single regression models (Section 3.4.4), and this was confirmed for both the $200 \mathrm{~m}$ isobath (near the shelf break) and a deeper $400 \mathrm{~m}$ isobath. We find that the mean-flow term dominates over the Ekman term in explaining the variability (Sections 3.4.4 and 3.5).

One additional component of the BBL transport previously considered was alongshore winds driving upwelling and downwelling (e.g. Ekman 1905; Niebauer et al. 1977). At some locations, the BBL and wind-driven Ekman transports have been shown to be in balance (e.g. Perlin et al. 2005) but only when the interior current is weak (e.g. Smith 1981). This has not been the case at other locations, e.g. Schaeffer et al. (2014), who additionally report poor correlations between the BBL and wind-driven Ekman transports. Here, we have shown the addition of a wind-driven Ekman 
(a) Across-slope BBL transport decorrelation length scale Across-slope BBL transport decorr
$r=0.5$ (red)

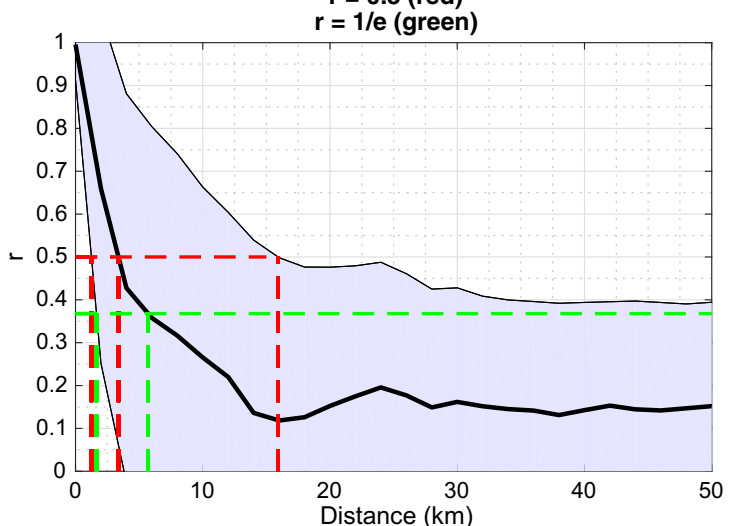

(c)

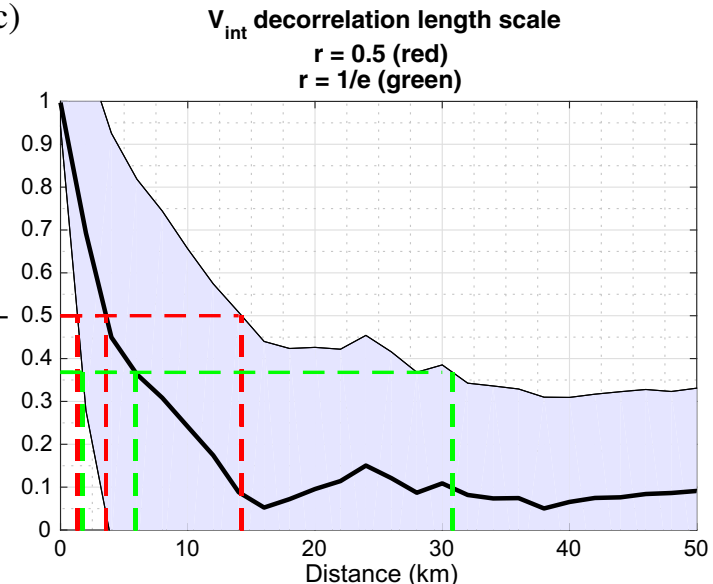

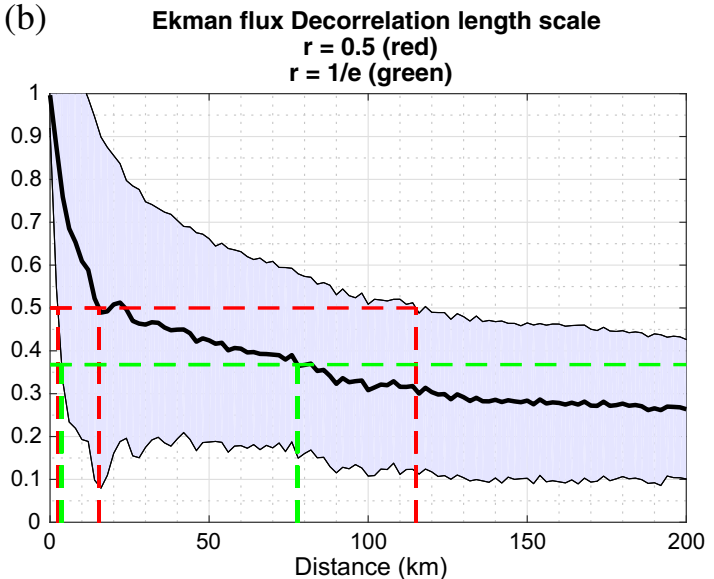

(d)

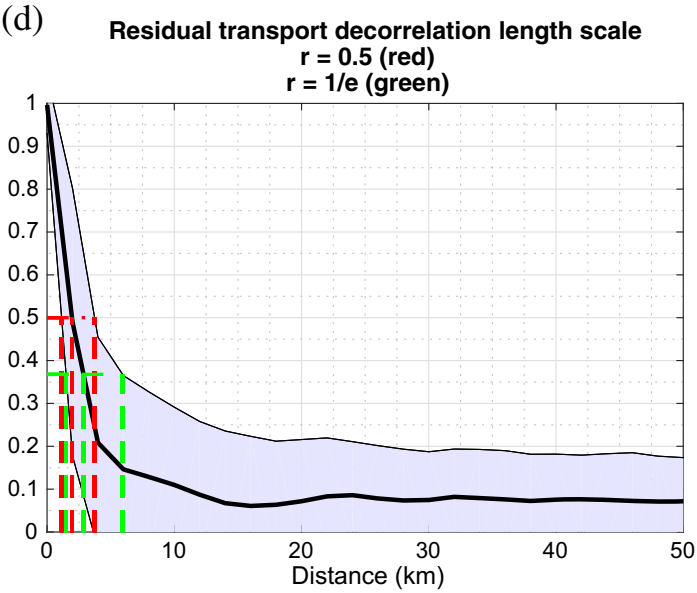

Fig. 15 Decorrelation plots calculated from spatial correlations of various transports, averaged and binned as a function of station separation distance, for: a across-slope BBL transport, $\mathbf{b}$ Ekman transport, $\mathbf{c}$ interior flux and $\mathbf{d}$ residual transports. The $\frac{1}{2}$-folding distances are shown for additional context

transport term, driving a local 2-D downwelling circulation, contributes little to further explaining the daily variability of the bottom fluxes.

The power of our regression approach on model data has enabled us to disentangle the components of the BBL fluxes, for many locations all on the shelf-break and for a few years of data-which is not yet achievable through observations alone given their sparsity. We do not claim that our regression model and coefficients can be used to accurately predict $\mathrm{BBL}$ fluxes for observational data that do not extend to the near seabed. In practice, the coefficients that we have established for our regression coefficients are not spatially fixed, and so it is not clear which to use for a predictive model. What we have shown is that any model of BBL fluxes that does not extend to the seabed should take into consideration both Ekman and mean-flow terms, but a 2-D wind-forced downwelling term is not required.

The seasonal variability of the Shetland slope current inflow (i.e. flow parallel to the slope rather than across the slope) was investigated by Gould et al. (1985) who reported a sinusoidal seasonal variability of inflow with maximum in winter and minimum in summer. Sherwin et al. (2008) find a similar low in summer but consistently high inflow for the majority of the year. The seasonal variability of the Hebridean slope current was studied by Souza et al. (2001). They find the across-slope velocity is offshore and stronger in winter than in summer (over the entire water column and not just the BBL). They link this to changes in the windstress which become more off-shore favourable in the winter than summer. We provide for the first time a seasonal perspective of across-slope BBL transport on the Shetland shelf (Fig. 10; Section 3.3) and find it also has a sinusoidal pattern with a winter-high and summer-low. This is also reflected in the components of BBL transport (Ekman and mean-flow terms). Sherwin et al. (2008) provide a time-series of southwesterly wind stress and attempt to connect it to the inflow variability. There is a clear similarity between their wind time-series and our BBL transport time-series. It may be that the wind influences the interior slope current on seasonal time-scales and therefore the across-slope BBL transport (a 
result of our regression analysis). However, this connection between the wind and the BBL transport via the interior current is implicit rather than explicit: we have shown that an explicit wind-driven 2-D downwelling term is not required in explaining the BBL transport (Sections 3.4.5 and 3.5).

The magnitude of BBL transport was previously estimated in a model study of the north-west European continental shelf by Holt et al. (2009). They used a $\sigma$-coordinate model which ran for 44 years at $\sim 12 \mathrm{~km}$ resolution. For their section of the Shetland shelf, they found, for the same $20 \mathrm{~m}$ BBL height, a similar Ekman transport (0.16 Sv vs. $0.15 \mathrm{~Sv}$ here). This is encouraging given one limitation with our transport estimates is that we have only simulated four years. However, they do report less BBL transport $(0.28 \mathrm{~Sv}$ vs. $0.53 \mathrm{~Sv}$ here). Differences between estimates could be due to inter-annual variability and the lateral extent of the isobath used. The correlation between single Ekman-drain models is also similar $\left(R^{2}=0.24\right.$ vs. shelf-mean $R^{2}=0.25$ here). We show here that a large part of the unaccounted BBL transport is due to the $V_{\text {int }}$ component of the interior current which we estimate to be $0.31 \mathrm{~Sv}$. This was previously not attributed.

For both the variability and magnitude, the orientation method used to define the across- and along-slope direction of the interior flow will affect flux estimates. An assumption for the Shetland slope current (e.g. Turrell et al. 1992; Simpson and McCandliss 2013) is that the interior current direction (here $\theta^{T P T}$ ) can be used as proxy for the true bathymetric direction (here $\theta^{L G}$ ), and from that estimates of the across-slope transport can be made. If this is not the case (i.e. the mean flow direction is not parallel to the slope), then such estimates will be different to the true across-slope transport. Souza et al. (2001) find the Hebridean slope current is closely parallel to the isobaths. We find the Shetland slope current at the $200 \mathrm{~m}$ isobath is directed $5^{\circ}$ off-shelf, so nearly parallel but not exactly (Section 3.2). We have shown that using a mean-flow orientation method $\left(\theta^{T P T}\right)$ dampens the mean-flow contribution to across-slope BBL transport, whilst enhancing that of the Ekman transport (Section 3.5). This effect must be better considered in future estimates.

The spatial scale of the Ekman drainage is approximately $80 \mathrm{~km}$ whereas the $V_{i n t}$ transport is more local (Figs. 15 and 16). Brink and Robinson (2005) have previously stated that the decorrelation length of the along-slope current is larger than for the across-slope current. The large alongshelf coherence of the Shetland slope current (Figs. 3 and 9) causes a large spatial coherence of the Ekman transport. For $V_{i n t}$, the mean $e$-folding distance is about $5 \mathrm{~km}$ but within errors this is $\mathrm{O}(10 \mathrm{~km})$ demonstrating a range of scales for this process. Sherwin et al. (2006) analyse slope current meanders of $\mathrm{O}(10 \mathrm{~km})$ and their contribution to shelf-edge exchange. They suggested it was likely these meanders break down to smaller eddies, hinting a range of scales for shelf-edge exchange. Our decorrelation plots for the $V_{\text {int }}$ and BBL transport are similar (Fig. 16) and it is apparent that the short scale of $V_{\text {int }}$ has consequences for BBL transport. It is precisely the localisation of $V_{i n t}$ transport that causes localisation of BBL transport. By capturing the mean-flow on smaller scales we capture more of the short-term variability in the BBL transport.

Utilising a multivariate regression approach, we have provided insight into the variability, magnitude and spatial scale of the various BBL transports. We now consider potential sources of local residual behaviour. Residuals lead to variability of the BBL transports around the best fit which decreases local correlation. Firstly, one of the primary assumptions of Ekman theory is that the interior ocean current does not accelerate: it is in steady state. Acceleration of the interior current, $\mathbf{V}_{\text {int }}$, may not correspond directly to the BBL transport. Stewart (2004) states acceleration of currents are important for horizontal scale of less than $50 \mathrm{~km}$ and for less than a few days. We attempt to remove the effect

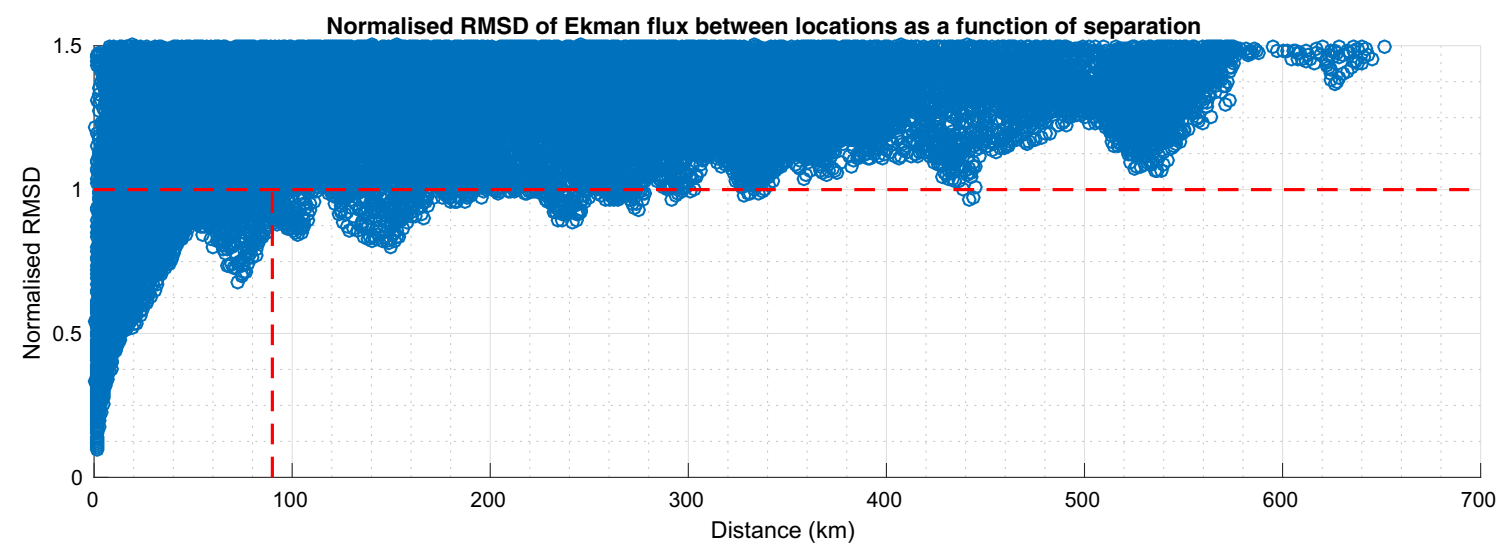

Fig. 16 Decorrelation plot calculated from normalised root-mean square deviation (RMSD) between locations for the Ekman flux time-series. The RMSD is normalised from the mean value of the first time-series 
of acceleration by time averaging our currents but we find that the correlation does not improve with time averaging, making this an unlikely explanation.

One limitation in the multivariate regression is a larger veering layer in our simulation. If this increases into the assumed depth we have taken for the interior current $\mathbf{V}_{\text {int }}$ (Section 2.3), then the two sides in our regression equation (5) are not independent. A veering layer develops because of the turbulent transfer of momentum upwards from the boundary stress, parametrised by the vertical eddy viscosity: increasing this will increase the height of the veering layer. The basic Ekman model (Ekman 1905) uses a constant eddy viscosity to derive a veering layer height. Cushman-Roisin and Malačič (1997) show in an unstratified boundary layer the eddy viscosity may vary proportionally to the boundary distance. It is also known that the veering layer height varies with vertical mixing and stratification, for both the surface (e.g. Lentz 2001) and bottom layers (e.g. Perlin et al. 2005). Vertical mixing and stratification are linked: the presence of stratification inhibits vertical (diapycnal) mixing. Conversely mixing of light and denser bottom waters increases the vertical turbulence and decreases stratification by homogenising the waters. Increased vertical turbulence increases the vertical eddy viscosity, thus increasing the veering layer height. Stratification and veering have been considered in Perlin et al. (2007) for the Oregon coast who report veering layers of around $20 \mathrm{~m}$, and observed by Hosegood and van Haren (2003) in the FSC with veering up to $50 \mathrm{~m}$ above the seabed. Hosegood and van Haren (2003) additionally considered the effect of the slope on the veering height for the Shetland shelf (using Trowbridge and Lentz 1991), providing a minimum value of $8.3 \mathrm{~m}$ with the strongest stratification and increasing inversely with the buoyancy frequency to potentially $\mathrm{O}(100 \mathrm{~m})$. In our model, stratification profiles are reasonable compared to observations (Fig. 8). Furthermore, we have attempted to mitigate the assumption of a fixed veering layer of $20 \mathrm{~m}$ by taking the interior current as the depth-averaged current in the $80 \mathrm{~m}$ layer above the proposed BBL. We also tested our regression model at the $400 \mathrm{~m}$ isobath where it was also valid.

An additional complication is the difficulty of the MIT$\mathrm{gcm}$, a z-coordinate model, in allowing dense water to flow down-slope, as discussed by Legg et al. (2006). They show that the amount of dense water overflowing in the MIT$\mathrm{gcm}$ is dependent on the model resolution-coarse models generate excessive spurious mixing preventing dense water from descending. At intermediate resolutions, the model produces less mixing and more dense water can descend, though less than their non-hydrostatic simulations run at the highest resolution. Intermediate resolutions also produced similar levels of mixing as compared to isopycnal models. Our model was run (Section 2.1) between intermediate to high resolution using their benchmarks, and it is therefore likely to be suitable to simulate downslope flows.

\section{Conclusions}

We have presented a high-resolution model of the FaroeShetland Channel that simulates many features seen in observations (e.g. Sherwin et al. 1999; Berx et al. 2013). We have developed a multivariate regression model of acrossslope BBL transport, to understand its daily variability, as a function of the along- and across-slope components of the interior flow. These terms correspond to an Ekman and mean-flow term. The inclusion of the mean-flow term represents an improvement over previous Ekman-only models of the BBL transport (Holt et al. 2009; Simpson and McCandliss 2013). We also reject 2-D wind-forced downwelling as a variable in explaining the daily variability of the BBL transport. We also attribute a greater portion of the BBL transport budget to the mean-flow compared to the Ekman transport. A previous study with similar Ekman transport (Holt et al. 2009) had not done this.

For the first time, we have presented a seasonal cycle for the across-slope BBL transport and found it has a winterhigh and summer-low, similar to the interior flow of the Hebridean slope current (Souza et al. 2001). Sherwin et al. (2008) connects the wind on seasonal timescales with the seasonal inflow variability of the slope current. From our study, the interior slope current directly explains the BBL transport variability. We have also rejected the explicit role of the wind, in the form of a 2-D downwelling term, in explaining the variability of the BBL transport. Therefore if the wind does play a role in explaining the seasonal BBL transport, this connection is implicit and via a modification of the interior current.

We have estimated the average scale of the Ekman transport to be over $80 \mathrm{~km}$, near-grid scale $(<5 \mathrm{~km})$ for the mean-flow and the BBL transport, and sub-grid scale for the residual behaviour. Local mean-flow is therefore important in determining shelf-edge exchange.

Our regression method is general and may be used to diagnose the contribution of Ekman, mean-flow and the wind to across-slope BBL fluxes in models. In the simple Ekman-drain model, it is only the change in interior current speed that explains the BBL flux variability. Here, we show that for this region, the variation in direction of the interior flow is of greater importance in understanding the BBL transport.

Acknowledgments AT was funded by an EPSRC CASE award with BP plc. The authors would like to thank BP plc. for providing the current observations, B. Berx for usage of figures and two anonymous reviewers for their contributions to improving this work. 
Open Access This article is distributed under the terms of the Creative Commons Attribution 4.0 International License (http:// creativecommons.org/licenses/by/4.0/), which permits unrestricted use, distribution, and reproduction in any medium, provided you give appropriate credit to the original author(s) and the source, provide a link to the Creative Commons license, and indicate if changes were made.

\section{References}

Berx B, Hansen B, Østerhus S, Larsen K, Sherwin T, Jochumsen K (2013) Combining in-situ measurements and altimetry to estimate volume, heat and salt transport variability through the FaroeShetland Channel. Ocean Sci 9(4):639-654

Böhme L, Send U (2005) Objective analyses of hydrographic data for referencing profiling float salinities in highly variable environments. Deep-Sea Res II Top Stud Oceanogr 52(3):651-664

Bowden K (1953) Note on wind drift in a channel in the presence of tidal currents. In: Proceedings of the Royal Society of London A: mathematical, physical and engineering sciences, the royal society, vol 219, pp 426-446

Bozec Y, Thomas H, Elkalay K, de Baar HJ (2005) The continental shelf pump for $\mathrm{CO}_{2}$ in the North Sea-evidence from summer observation. Mar Chem 93(2):131-147

Brink KH, Robinson AR (2005) The global coastal ocean: processes and methods, vol 10. Harvard University Press

Broadbridge MB, Toumi R (2015) The deep circulation of the FaroeShetland Channel: opposing flows and topographic eddies. J Geophys Res Oceans 120(9):5983-5996

Burrows M, Thorpe S (1999) Drifter observations of the Hebrides slope current and nearby circulation patterns. Springer 17:280302

Chafik L (2012) The response of the circulation in the Faroe-Shetland Channel to the North Atlantic Oscillation. Tellus A:64

Chassignet EP, Hurlburt HE, Smedstad OM, Halliwell GR, Hogan PJ, Wallcraft AJ, Baraille R, Bleck R (2007) The HYCOM (HYbrid Coordinate Ocean Model) data assimilative system. J Mar Syst 65(1):60-83

Cushman-Roisin B, Malačič V (1997) Bottom Ekman pumping with stress-dependent eddy viscosity. J Phys Oceanogr 27(9):19671975

Donlon CJ, Casey KS, Robinson IS, Gentemann CL, Reynolds RW, Barton I, Arino O, Stark J, Rayner N, Le Borgne P, et al. (2009) The GODAE high resolution sea surface temperature pilot project. Oceanography 22(3):34-45

Dooley H, Martin J, Payne R (1976) Flow across the continental slope off Northern Scotland. Elsevier 23:875-880

Ekman VW (1905) On the influence of the Earth's rotation on ocean currents. Ark Mat Astron Fys 2:1-53

Frankignoulle M, Borges AV (2001) European continental shelf as a significant sink for atmospheric carbon dioxide. Glob Biogeochem Cycles 15(3):569-576

Gould W, Loynes J, Backhaus J (1985) Seasonality in slope current transports NW of Shetland. ICES CM 100:7

Hansen B, Østerhus S (2000) North Atlantic-Nordic Seas exchanges. Progress in Oceanography 45(2):109-208

Holt J, Wakelin S, Huthnance J (2009) Down-welling circulation of the northwest European continental shelf: a driving mechanism for the continental shelf carbon pump. Geophys Res Lett 36(14)
Hosegood P, van Haren H (2003) Ekman-induced turbulence over the continental slope in the Faroe-Shetland Channel as inferred from spikes in current meter observations. Deep-Sea Res I Oceanogr Res Pap 50(5):657-680

Hunter J (1975) A note on quadratic friction in the presence of tides. Estuar Coast Mar Sci 3(4):473-475

Huthnance JM (1995) Circulation, exchange and water masses at the ocean margin: the role of physical processes at the shelf edge. Prog Oceanogr 35(4):353-431

Huthnance JM, Holt JT, Wakelin SL (2009) Deep ocean exchange with West-European shelf seas. Ocean Sci 5(4):621634

Large WG, McWilliams JC, Doney SC (1994) Oceanic vertical mixing: a review and a model with a nonlocal boundary layer parameterization. Rev Geophys 32(4):363-403

Legg S, Hallberg RW, Girton JB (2006) Comparison of entrainment in overflows simulated by z-coordinate, isopycnal and non-hydrostatic models. Ocean Model 11(1):69-97

Lentz SJ (2001) The influence of stratification on the wind-driven cross-shelf circulation over the North Carolina shelf. J Phys Oceanogr 31(9):2749-2760

Marshall J, Adcroft A, Hill C, Perelman L, Heisey C (1997) A finite-volume, incompressible Navier Stokes model for studies of the ocean on parallel computers. J Geophys Res Oceans 102(C3):5753-5766

Niebauer H, Green T, Ragotzkie RA (1977) Coastal upwelling/downwelling cycles in southern Lake Superior. J Phys Oceanogr 7(6):918-927

Oey LY (1998) Subtidal energetics in the Faroe-Shetland Channel: coarse-grid model experiments. J Geophys Res Oceans 103(C6):12,689-12,708

Perlin A, Moum J, Klymak J (2005) Response of the bottom boundary layer over a sloping shelf to variations in alongshore wind. J Geophys Res Oceans 110(C10)

Perlin A, Moum J, Klymak J, Levine M, Boyd T, Kosro P (2007) Organization of stratification, turbulence, and veering in bottom Ekman layers. J Geophys Res Oceans 112(C5)

Pingree R, Le Cann B (1989) Celtic and Armorican slope and shelf residual currents. Prog Oceanogr 23(4):303-338

Ryther JH (1969) Photosynthesis and fish production in the sea. Science 166(3901):72-76

Saha S, Moorthi S, Pan HL, Wu X, Wang J, Nadiga S, Tripp P, Kistler R, Woollen J, Behringer D, et al. (2010) The NCEP climate forecast system reanalysis. Bull Am Meteorol Soc 91(8):10151057

Sandwell DT, Smith WH (1997) Marine gravity anomaly from GEOSAT and ERS1 satellite altimetry. J Geophys Res Solid Earth 102(B5): 10,039-10,054

Schaeffer A, Roughan M, Wood J (2014) Observed bottom boundary layer transport and uplift on the continental shelf adjacent to a western boundary current. J Geophys Res Oceans 119(8):49224939

Sherwin T, Turrell W, Jeans D, Dye S (1999) Eddies and a mesoscale deflection of the slope current in the FaroeShetland Channel. Deep-Sea Res I Oceanogr Res Pap 46(3):415438

Sherwin TJ, Williams MO, Turrell WR, Hughes SL, Miller PI (2006) A description and analysis of mesoscale variability in the FaroeShetland Channel. J Geophys Res Oceans 111(C3)

Sherwin TJ, Hughes SL, Turrell WR, Hansen B, Østerhus S (2008) Wind-driven monthly variations in transport and the flow field in the Faroe-Shetland channel. Polar Res 27(1):7-22 
Simpson JH, McCandliss RR (2013) The Ekman Drain: a conduit to the deep ocean for shelf material. Ocean Dyn 63(9-10):10631072

Smith RL (1981) A comparison of the structure and variability of the flow field in three coastal upwelling regions: Oregon, Northwest Africa, and Peru. Coastal Upwelling:107118

Souza AJ, Simpson JH, Harikrishnan M, Malarkey J (2001) Flow structure and seasonality in the Hebridean slope current. Oceanol Acta 24:63-76

Stewart RH (2004) Introduction to physical oceanography. Texas A \& M University
Thomas H, Bozec Y, Elkalay K, De Baar HJ (2004) Enhanced open ocean storage of $\mathrm{CO}_{2}$ from shelf sea pumping. Science 304(5673):1005-1008

Trowbridge J, Lentz S (1991) Asymmetric behavior of an oceanic boundary layer above a sloping bottom. J Phys Oceanogr 21(8):1171-1185

Tsunogai S, Watanabe S, Sato T (1999) Is there a "continental shelf pump" for the absorption of atmospheric $\mathrm{CO}_{2}$ ? Tellus $\mathrm{B}$ 51(3):701-712

Turrell W, Henderson E, Slesser G, Payne R, Adams R (1992) Hydrographic observations at the continental shelf edge northwest of Scotland. ICES Council Meeting Papers CM1992/C:19 